\title{
Post-elastic Deformation Characteristics of Hybrid Fibre Reinforced Concrete Composites
}

\author{
Sivakumar Anandan ${ }^{\mathrm{a}^{*}}$ (ID) Majed Alsubih ${ }^{\mathrm{a}}$ \\ a Department of Civil Engineering, College of Engineering, King Khalid University, Abha, Kingdom of Saudi Arabia. E-mail: ksiva@kku.edu.sa, \\ malsubih@kku.edu.sa
}

*Corresponding author

https://doi.org/10.1590/1679-78255851

\begin{abstract}
The present study was focused on evaluating the strength and failure properties of hybrid micro-fibre concretes containing micro brass and steel fibre additions. Experimental tests were conducted on different hybrid fibre concretes containing aligned fibres in the direction of beam axis and the relative mechanical performance was compared to randomly distributed fibre additions in concrete. Statistical analysis on the test results were used to compare the distinctive performance of fibre combinations at different dosage levels. The effect of binder to aggregate ratio and the varying proportions of fibre combinations on the concrete properties were assessed in terms of flexural strength, fracture toughness and ductility. The statistical analysis of the experimental results indicated the dual action of hybrid fibre combinations in improving the composite properties and the crack arresting mechanism of fibres at varying stages of loading as observed from the load-CMOD curves. Among the various concretes tested, the hybrid fibre concretes containing steel-brass fibres dosages at $1.0 \%$ and $0.03 \% \mathrm{~V}_{f}$ performed consistently in overall mechanical properties.
\end{abstract}

\section{Keywords:}

fracture, toughness, fibre reinforcement, ductility, deformation, hybrids

\section{Graphical Abstract}
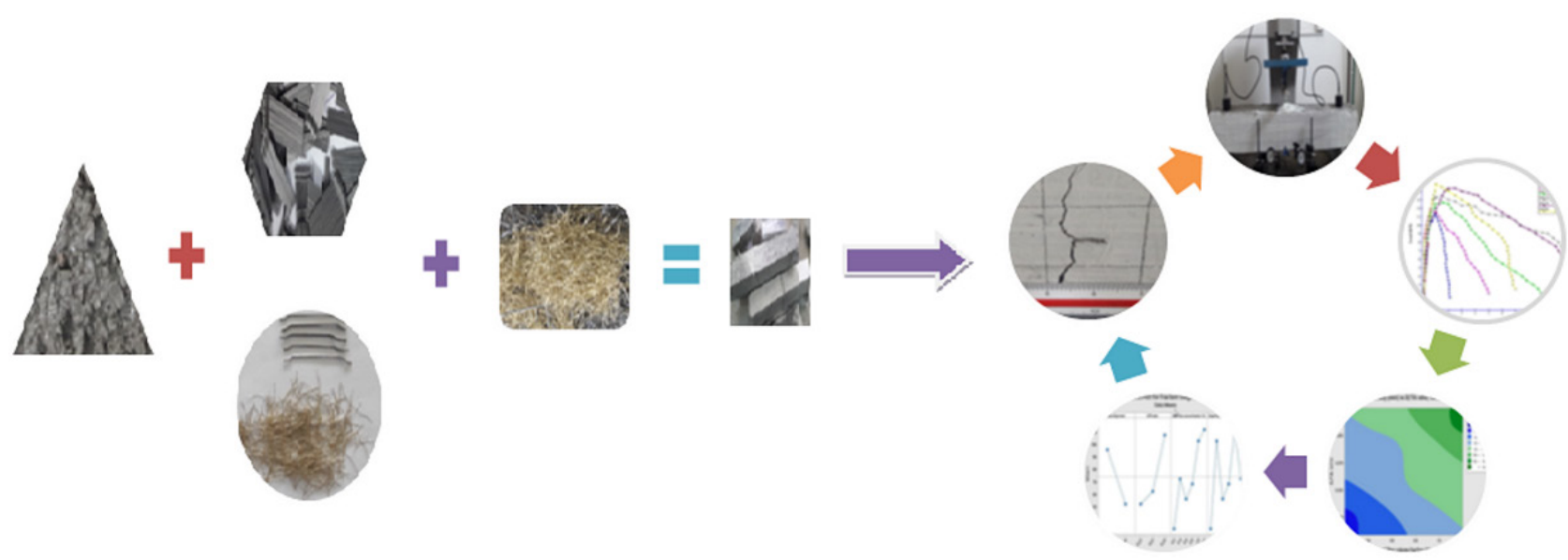

Received: October 29, 2019 In Revised Form: November 08, 2019 Accepted: November 09, 2019 Available online: November 11, 2019 http://dx.doi.org/10.1590/1679-78255851

(i) Latin American Journal of Solids and Structures. ISSN 1679-7825. Copyright @ 2019. This is an Open Access article distributed under the terms of the Creative Commons Attribution License, which permits unrestricted use, distribution, and reproduction in any medium, provided the original work is properly cited. 


\section{INTRODUCTION}

Fibre reinforcements using different types of fibres had been well investigated in many research studies. Plain concrete undergoes different types of stress mechanisms leading to severe structural deterioration necessitating the fatigue endurance. Many investigations over decades had significantly contributed towards achieving high quality concrete in terms of long-term sustainability for wider special applications. However, the basic problems in concrete arising out during the different harsh environmental conditions leads to internal stress cracking (e.g delayed ettringite formation and volumetric drying shrinkage) poses constraint in many concrete structural applications. Mechanisms leading to crack arresting during the stress transfer in cementitious matrix are well received in many research studies [Balaguru \& Shah, 1992].

Traditionally steel fibres had been consistent in improving the overall mechanical performance of the brittle system. Steel fibres with different types of profiles were studied and are known to improve the fibre matrix bonding with increased tensile resistance [Bentur and Mindess, 1990; Yoo, et al., 2014; Markovic et al., 2004]. The end anchorages of steel fibres were known to improve the fracture resistance with high fibre pullout resistance [Olivito \& Zuccarello, 2010]. The surface roughness and complex profiles of steel fibres increase the effective interfacial stress transfer from fibre to matrix [Peng et al., 2018]. Many investigations on the fibre pullout resistance had shown reliable improvements on the interfacial fibre matrix bond characteristics. The mechanical performance of fibre addition depends on critical factors such as aspect ratio, length, diameter, volume fraction/fibre count largely affects on the mechanical response [Dancygier \& Savir, 2006; Yoo et al., 2015].

It is well understood from the earlier studies that fibres tend to get distributed in random fashion due to non uniform fibre dispersion at the time of mixing of fibres in concrete. Limited studies had been conducted using hybrid fibres to evaluate its dual action in concrete matrix at different scales of cracking [Machine et al., 2008; Quian \& Stroeven, 2000; Kaan et al., 2019]. Studies have also suggested that reliable outcome of the fibre combinations depends on the orientation and dispersion of fibres in concrete matrix [Dancygier \& Berkover, 2016]. Hybrid fibre additions in concrete tends to reduce the workability and suitable addition of superplasticizers can improve the fibre balling thereby envisages the overall mechanical properties. The optimum fibre combinations in-terms of length, aspect ratio and volume fraction are desirable to achieve the synergistic interaction of fibres in concrete [Gao et al, 2019]. Studies in this direction have provided potential merits for tailoring the concrete properties. Some of the vital parameters that control the fibre performance are the calculated volume fraction of fibres, presence of short fibres and the orientation of fibres [Banyhussan et al., 2016; Soner et al., 2019]. In addition, the strong fibre-matrix bonding is necessarily important for achieving maximum pullout resistance. Tensile improvements of fibre concrete apparently increase due to load sharing characteristics andmost essentially with the higher degree of homogeneous fibre distribution. Analytical studies in fibre concrete indicated the efficiency of theoretical equations to predict the fibre pullout resistance on the load carrying capacity of the fibres. The sufficient bonding length and frictional bond resistance during fibre pullout are the known mechanisms identified in many studies.

The hybrid fibre action in concrete matrix still needs to be explored to identify the possible fibre influence in the cementitious matrix during crack widening. Better analysis on the overall flexural response during stressed condition of concrete sections requires experimental modeling parameters for evaluating the interaction effects of hybrid fibre combinations. In the present study statistical software has been used to analyze the mechanical effects of hybrid fibres (steel-Brass) and subjective conclusions based on fibre mechanics has been drawn to validate the fibre properties in matrix. The synergistic effects of hybrid fibres in concrete matrix has been systematically explored using both experimental and theoretical validations on the mechanical response at varying stress levels of loaded fibre concrete specimens.

\section{EXPERIMENTAL METHODOLOGY}

\subsection{Materials and properties}

Portland cement of 43 grade cement was used as binder and fine sand of crushed aggregates were used for matrix preparation. Locally crushed rock aggregates of $12.5 \mathrm{~mm}$ size were used in concrete production. The detailed properties of various concrete ingredients are provided in Table 1.

Table 1. Properties of concrete ingredients

\begin{tabular}{cccc}
\hline Properties & Cement & Fine sand & Aggregate \\
\hline Grade & 43 & $4.75 \mathrm{~mm}$ passing & $12.5 \mathrm{~mm}$ passing \\
\hline
\end{tabular}




\begin{tabular}{cccc} 
Specific gravity & 3.15 & 2.45 & 2.61 \\
$\begin{array}{c}\text { Average particle size }(\mathrm{mm}) / \text { Fineness } \\
\text { modulus }\end{array}$ & 0.015 & 2.36 & 7.14 \\
Bulk density $\left(\mathrm{kg} / \mathrm{m}^{3}\right)$ & 3140 & 2340 & 2560 \\
Mortar strength $\left(\mathrm{N} / \mathrm{mm}^{2}\right)$ & & $46.34 \mathrm{~N} / \mathrm{mm}^{2}$ & \\
\hline
\end{tabular}

\subsection{Fibre types used}

Macro double hooked steel fibres and micro brass fibres were used in this study (as shown in Figure 1) for evaluating the fibre synergy and interaction effects on the overall mechanical properties of concrete. The basic properties of fibresused in this study are tabulated in Table $\mathbf{2}$ and these fibres were added in concrete homogenously by means of mechanical dispersion and the spreading of fibres in various layers of concrete were ensured.

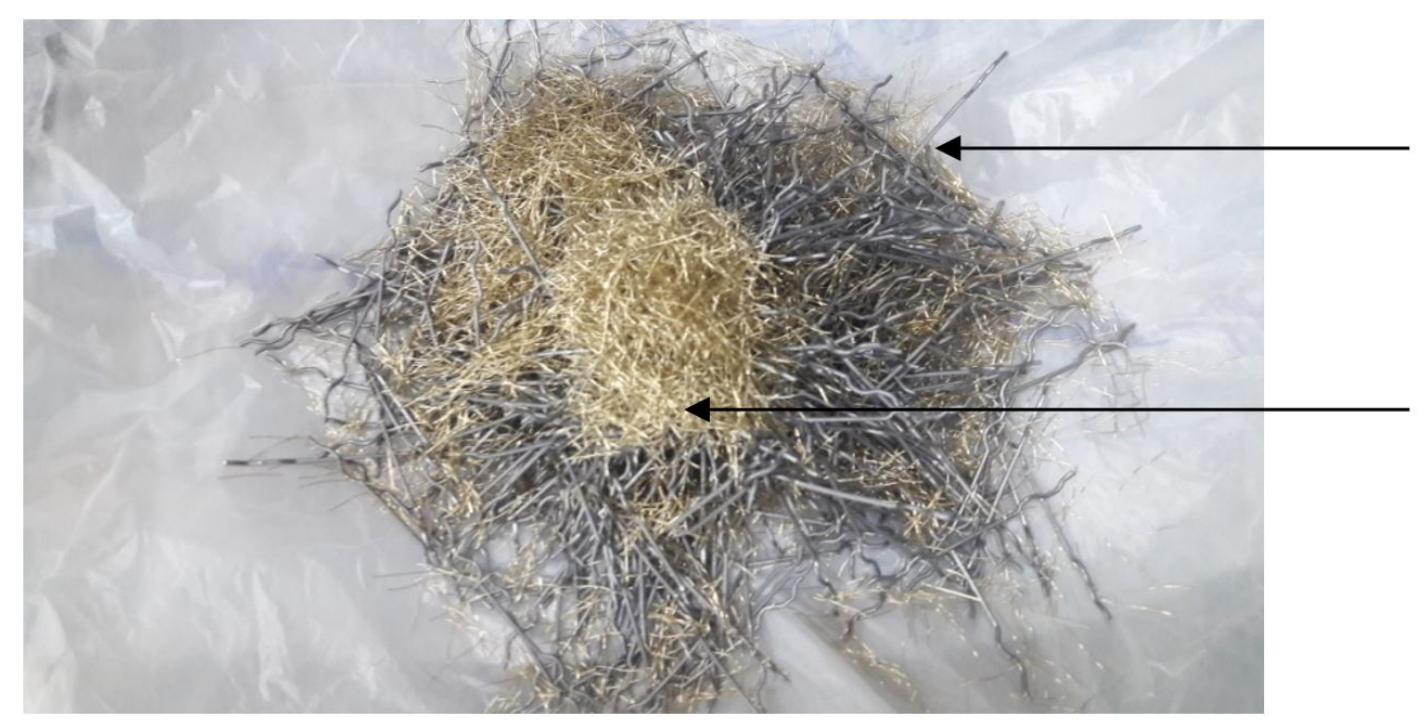

Steel fibres

Figure 1. Hybrid reinforcements used in this study - steel and brass fibres

\section{Brass fibres}

Table 2. Properties of fibres used in this study *

\begin{tabular}{cccccc}
\hline Type of fibres & Length $(\mathbf{m m})$ & Diameter $(\mathbf{m m})$ & Aspect ratio $(\mathrm{I} / \mathbf{d})$ & Tensile strength (MPa) & Failure strain $(\%)$ \\
\hline Double hooked steel & 32 & 0.48 & 67 & 420 & 8 \\
Micro Brass & 6 & 0.012 & 500 & 465 & 53 \\
\hline
\end{tabular}

*as provided by the fibre suppliers

\subsection{Fresh concrete production}

Concrete mixes were designed as per standard procedure [ACl-544, 2018] for a target compressive strength of $40 \mathrm{~N} / \mathrm{mm}^{2}$ and was proportioned based on the basic ingredients. As the study was mainly focused on the effect of fibre addition in different cementitious matrix, the binder to aggregate ratio was varied to study its influence in the concrete properties. The detailed concrete proportions are provided in Table 3. Also, the effect of hybrid fibres in different proportions and the alignment of fibres are taken as categorical variables.The significant effect of these factors affecting the mechanical properties of concrete are investigated. The details of the different hybrid fibre combinations and its corresponding constituent mixes are provided in Table 4.

Table 3. Concrete proportions used in the experimental study

\begin{tabular}{cccc}
\hline Mix Constituents & B/TA ratio $=\mathbf{0 . 2 3}$ & B/TA ratio $=\mathbf{0 . 2 7}$ & B/TA ratio $=\mathbf{0 . 3 0}$ \\
\hline Cement $\left(\mathrm{kg} / \mathrm{m}^{3}\right)$ & 412.23 & 452.15 & 430.8 \\
Sand $\left(\mathrm{kg} / \mathrm{m}^{3}\right)$ & 650.21 & 632.17 & 618.04 \\
Coarse Aggregate $\left(\mathrm{kg} / \mathrm{m}^{3}\right)$ & 1153.30 & 1073.45 & 1034.24 \\
w/c ratio & 0.38 & 0.38 & 0.38 \\
Water $\left(\mathrm{kg} / \mathrm{m}^{3}\right)$ & 165.34 & 156.65 & 163.70 \\
\hline
\end{tabular}


Superplasticizer $\left(\mathrm{kg} / \mathrm{m}^{3}\right)$

Concrete compressive strength $(28$ days)

Steel $\left(\mathrm{kg} / \mathrm{m}^{3}\right)$

Brass
2.0

41.23(RCM1)
2.3

44.61(RCM2)
2.1

42.56(RCM3)

\begin{tabular}{cccc}
0.6 & 0.8 & 1 & 1.2 \\
0.07 & 0.05 & 0.03 & 0.09 \\
\hline
\end{tabular}

Note: RCM1, RCM2, RCM3 - refers to reference concrete mixes

The different fibre proportions for preparing the hybrid fibre concrete mixes are given in Table 4 . It can be noted that the combinations of fibres in various proportions are added to the reference concrete mixes respectively for a selected B/TA (binder to aggregate ratio) given in Table 3.

Table 4. Fibre proportions used in the study

\begin{tabular}{ccccc}
\hline Mix ID & Fibre alignment & B/TA ratio & $\begin{array}{c}\text { Steel fibre volume fraction } \\
\text { (\%) }\end{array}$ & $\begin{array}{c}\text { Brass fibre volume } \\
\text { fraction (\%) }\end{array}$ \\
\hline S-B-021 & random & 0.23 & 0.2 & 0.01 \\
S-B-129 & aligned & 0.30 & 1.2 & 0.09 \\
S-B-087 & aligned & 0.27 & 0.8 & 0.07 \\
S-B-103 & random & 0.30 & 1.0 & 0.03 \\
S-B-065 & random & 0.27 & 0.6 & 0.05 \\
S-B-041 & aligned & 0.23 & 0.4 & 0.11 \\
\hline
\end{tabular}

Not: volume fraction of fibresrefers to $\%$ by total volume of concrete

\subsection{Mixing, casting and curing of concrete specimens}

Raw ingredients of concrete with calculated proportions as provided in Table $\mathbf{2}$ are added into a standard concrete mixer of $100 \mathrm{Kg}$ capacity and dry mixed initially. Later the required amount of mix water and superplasticizer (CERAPLAST-300) were added to the concrete mixer followed by the addition of fibres. The wet mix is then transferred to the required moulds and casted. After sufficient concealed curing ( 28 days) the hardened concrete specimens were tested respectively and the details of the specimens tested are provided in Table $\mathbf{5}$. A total of 9 concrete mixes were casted (as shown in Figure 2); out of which 3 were reference concrete mixtures (without fibres) namely RCM1, RCM2 and RCM3. Similarly the hybrid fibre concrete mixes are designated with the first two letters representing the steel (S) and brass (B) fibres followed by the volume fractions respectively (S-B-021, S-B-129, S-B-087, S-B-103, S-B-065, S-B041).

Table 5. Details of the concrete specimens casted and tested

\begin{tabular}{|c|c|c|c|c|}
\hline Type of testing & Size of specimen & $\begin{array}{l}\text { Curing age of concrete } \\
\text { (days) }\end{array}$ & $\begin{array}{c}\text { Number of specimens } \\
\text { tested }\end{array}$ & Parameters evaluated \\
\hline Compression & $150 \mathrm{~mm}$ cubes & 28 & 5 & Compressive strength \\
\hline Flexural Bending & $\begin{array}{l}\text { 100X100X100 mm } \\
\text { prism }\end{array}$ & 28 & 5 & $\begin{array}{c}\text { Fracture strength, toughness, } \\
\text { ductility }\end{array}$ \\
\hline
\end{tabular}




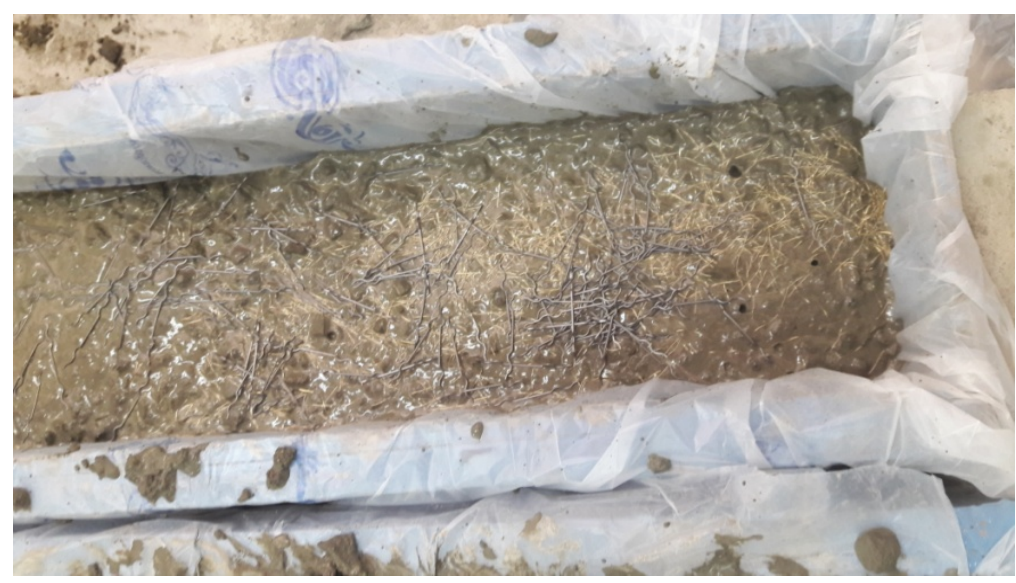

Figure 2. Casting of hybrid fibres aligned to beam axis - layered casting

\subsection{Experimental Testing}

Hardened concrete properties were tested as per standard [ASTM C-39, 2018] procedures. Compressive strength of concrete cubes of size $150 \mathrm{~mm}$ was carried in a compressive testing machine (1000KN capacity). Flexural properties of concrete were tested using prism specimens of size $100 \mathrm{~mm}$ X 100mm X 100mm and RILEM TC [1985] standard specifications was used for the fracture testing.

\subsubsection{Experimental Test setup}

Mortar tests were carried out as per ASTM C-39 [2018] and the standard test setup is shown in Figure 3.

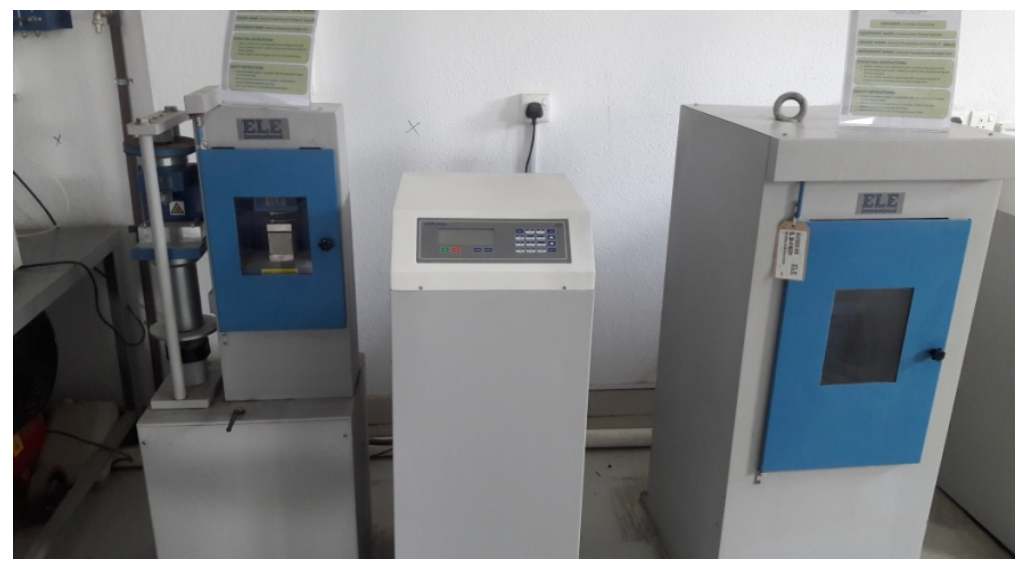

Figure 3. Mortar test setup

Flexural bending tests were carried out as per RILEM TC -1985 [Vandewalle et al., 2002] and the standard test setup shown in Figure 4. Load controlled flexural machine of capacity 100KN was used to conduct flexural tests and displacements were measured using two mechanical dial gauges fixed to the crack notch (10mm depth and $5 \mathrm{~mm}$ wide) opening (as shown in Figure 5). The average crack opening displacements are measured to compute the fracture toughness value for all the tested fibre concrete specimens. The absolute toughness was calculated from the entire load-crack opening displacement till the point of complete failure of concrete specimens. The macro cracks were measured using graduated scale as shown in Figure 6. 


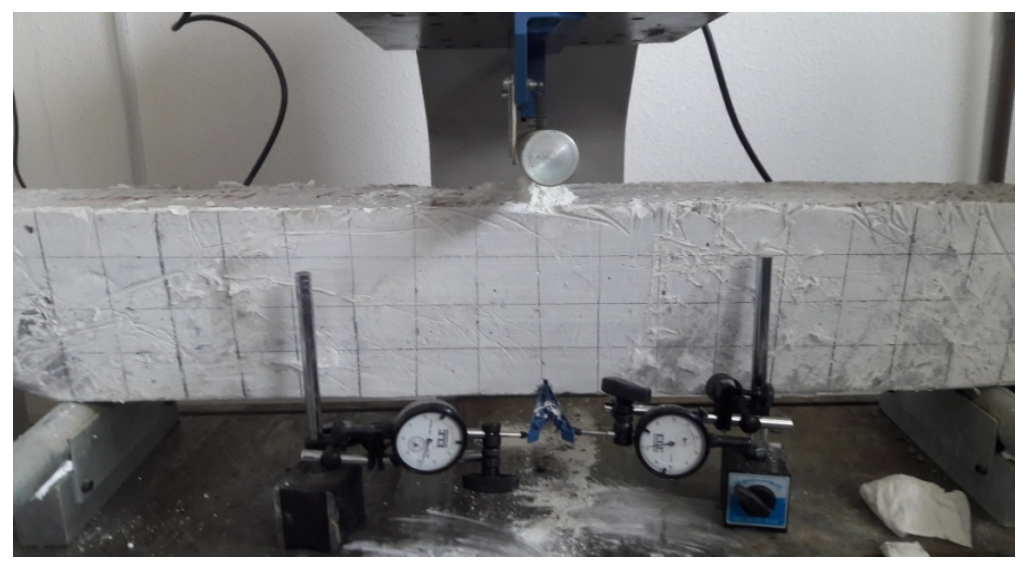

Figure 4. Flexural bending test setup

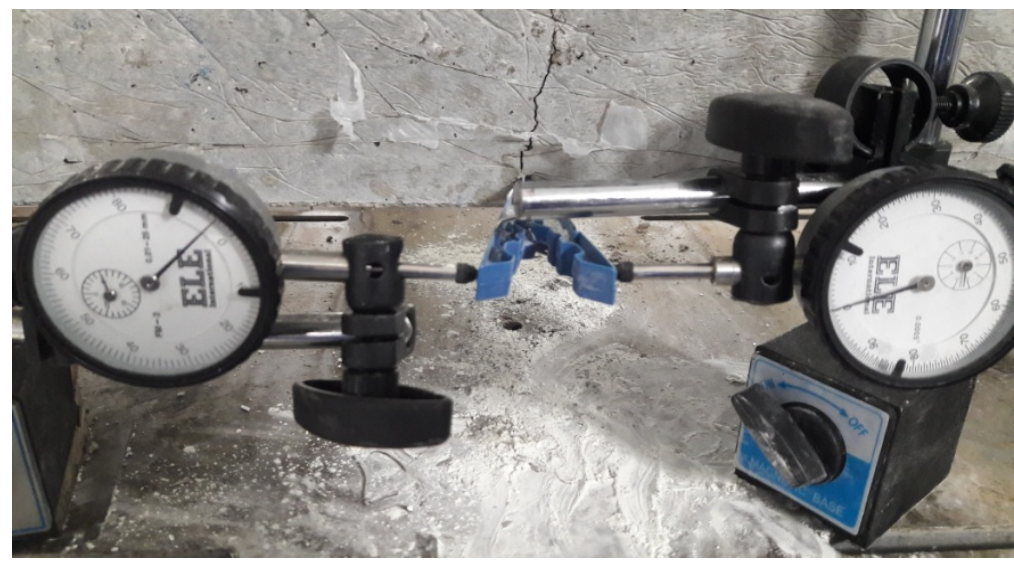

Figure 5. Micro-crack opening displacement measured using mechanical dial gauges

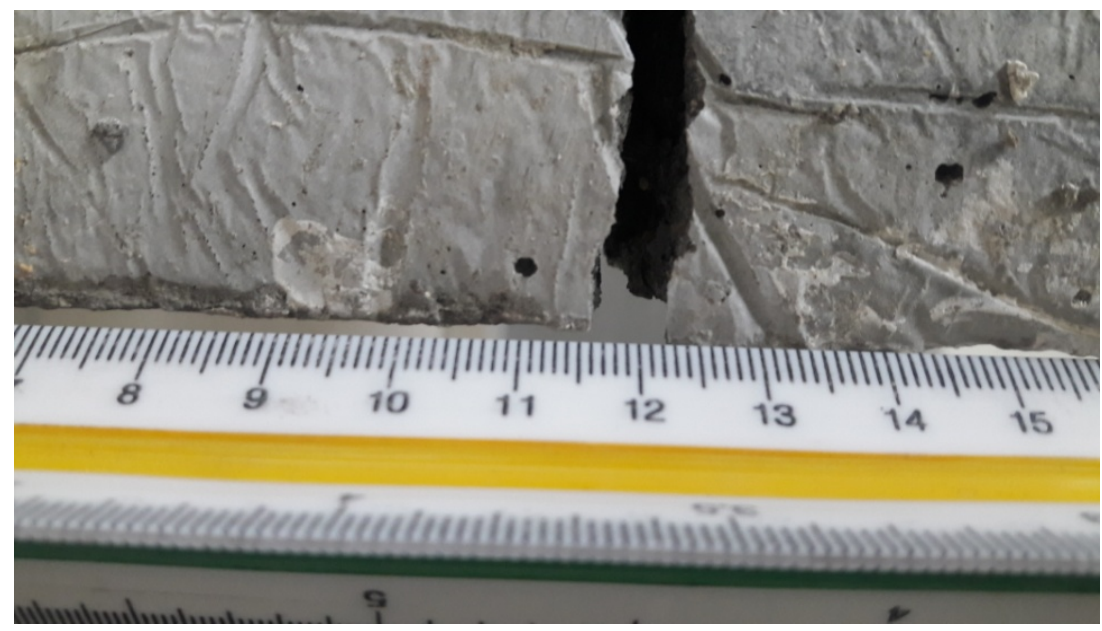

Figure 6. Macro- crack opening measured using graduated scale

\subsubsection{Flexural measurements}

i) Flexural strength of notched specimens were calculated from the following equation

$f_{c r}=P . L / b \cdot\left(d-d_{c}\right)^{2}(1)$

Where, $f_{c r}$ flexural strength of notched concrete specimen $\left(\mathrm{N} / \mathrm{mm}^{2}\right)$

$\mathrm{P}$ - failure load (KN)

$\mathrm{L}$ - length of specimen $(500 \mathrm{~mm})$

$\mathrm{b}$ - breadth of specimen $(\mathrm{mm})$

$\mathrm{d}$ - depth of specimen $(100 \mathrm{~mm})$

$\mathrm{d}_{\mathrm{c}}$ - notch depth $(10 \mathrm{~mm})$ 
ii) Fracture toughness

$F_{t}=$ area under the entire Load vs.CMOD plot calculated using graphical method

$F_{t}=\int P . \Delta(2)$ Where, $F_{t}$ Fracture toughness $(N-m)$

$P$ - failure load (KN)

$\Delta-$ crack mouth opening displacement (CMOD, $\mathrm{mm}$ )

\subsection{Experimental Design Models}

Experimental models were simulated and tested for its appropriateness in predicting the dual fibre action in concrete matrix. Initially, different hybrid fibres of varying proportions were randomly selected for testing using statistical design software. The observations of the experimental design were formulated systematically to find the effects of the factors affecting the overall response of the hybrid fibre combinations in the concrete system. In order to analyze the effects of steel and brass fibres in the concrete matrix four different factors were identified to affect the overall response of the concrete namely Fibre alignment, binder to total aggregate ratio, steel fibre and brass fibre dosage. The measured responses of the experimental design are flexural strength, fracture toughness and ductility of hybrid fibres. The experimental design were formulated in order to conduct random experiments to evaluate the maximum fibre performance. Hence, experiments were formulated in random order to evaluate the influence of varying fibre properties and proportions on the overall concrete properties. The results were analyzed, interpreted using regression equations and hence the outcome of the experimental results can provide the individual effects of various factors responsible for the overall composite response of the hybrid fibre concrete system. The detailed experimental plan carried out in this study is provided as flow chart in Figure $\mathbf{7}$ and detailed factors are given inTable $\mathbf{6}$.

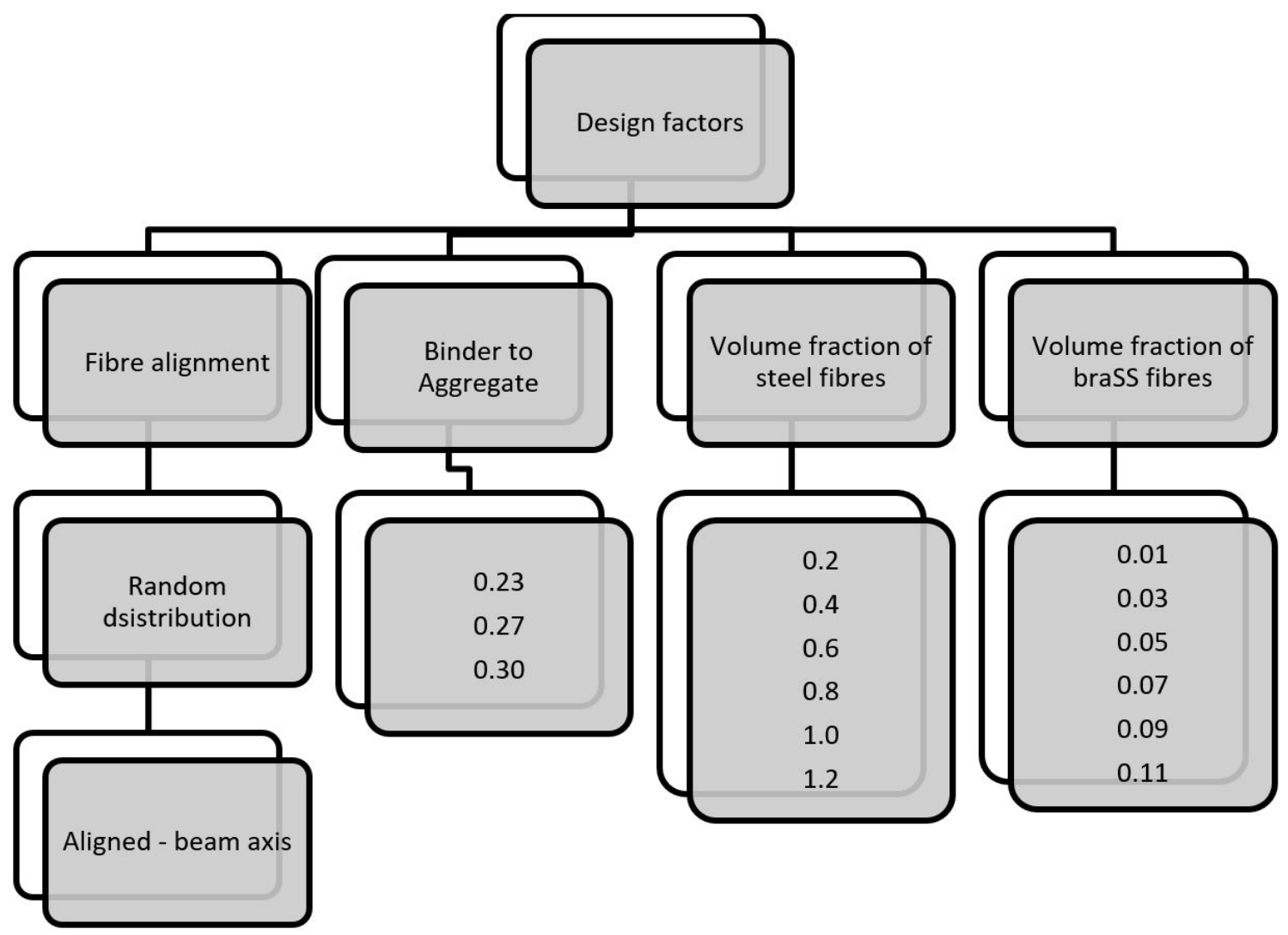

Figure7. Experimental design plan of the study

Table 6. Experimental design factors used in this study

\begin{tabular}{ccccc}
\hline Mix ID & Fibre alignment & B/TA* ratio & Steel fibre volume fraction (\%) & Brass fibre volume fraction (\%) \\
\hline S-B-021 & random & 0.23 & 0.2 & 0.01 \\
S-B-129 & aligned & 0.3 & 1.2 & 0.09 \\
S-B-087 & random & 0.27 & 0.8 & 0.07 \\
\hline
\end{tabular}




\begin{tabular}{lllll} 
S-B-103 & aligned & 0.3 & 1.0 & 0.03 \\
S-B-065 & random & 0.27 & 0.6 & 0.05 \\
S-B-041 & aligned & 0.23 & 0.4 & 0.11 \\
\hline
\end{tabular}

Note $*$ denotes binder to aggregate ratio

\section{TEST RESULTS AND DISCUSSIONS}

\subsection{Compressive performance of hybrid fibre concretes}

Compressive test results of the various fibre concrete mixes are provided graphically in Figure 8. The addition of large volume fraction (1\%) of steel fibres compared to brass fibres volume fraction in concrete matrix has not shown considerate increase in compressive strength. On the other hand, the gradual increase in brass fibre volume fraction with the reduction in steel fibre volume fraction had shown consistent improvements on compressive strength. However, a maximum strength of $47.06 \mathrm{~N} / \mathrm{mm}^{2}$ was obtained with optimum steel-brass fibre (S-B-065) combinations of 0.6 and $0.5 \% V_{f}$ respectively. The cementitious matrix is efficiently reinforced with fine brass fibres as compared to coarse steel fibres. In the case of high volume of steel fibres with large spacing, the interception of crack plane with fibres didn't occur significantly thus not developing effective crack arresting mechanism. The improvement in compressive strength was noticed with the gradual increase in the brass fibre addition in the hybrid fibre concretes. The fineness of brass fibres envisage more improved matrix strengthening and delay in micro crack formation. In addition, the effect of binder to aggregate ratio had shown consistent influence on the fibre performance in the cementitious matrix. With the increased binder to aggregate ratio $(0.3)$ the compressive properties of concrete had been relatively improved. However, it was evidently noticed during the progress of loading, the concrete specimens showed multiple cracking outside the concrete surface with cracks spreading unconditionally at failure. Fibres in general do not actively take part in load resistance in compression even though the crack trajectory might intercept with fibres. As the process of failure involves in crushing of matrix-aggregate particles rather than produce a direct tensile force in which case fibres didn't have a significant role in load sharing. However, the presence of micro brass fibres possibly strengthened the matrix resulting in some appreciable increase in all hybrid fibre concretes. This can be evidently seen with an optimum addition of brass fibres in the range of 0.05 to $0.07 \%$ provides reasonable matrix strengthening. Whereas, for maximum steel fibre substituted concretes the resulting compressive performance was not satisfactorily higher than other fibre concrete types. It can be concluded that fibre addition cannot be anticipated to provide a higher improvements in compressive strength; but on the other hand fibres control the sudden bursting of concrete leading to controlled failure without splitting into fragments.

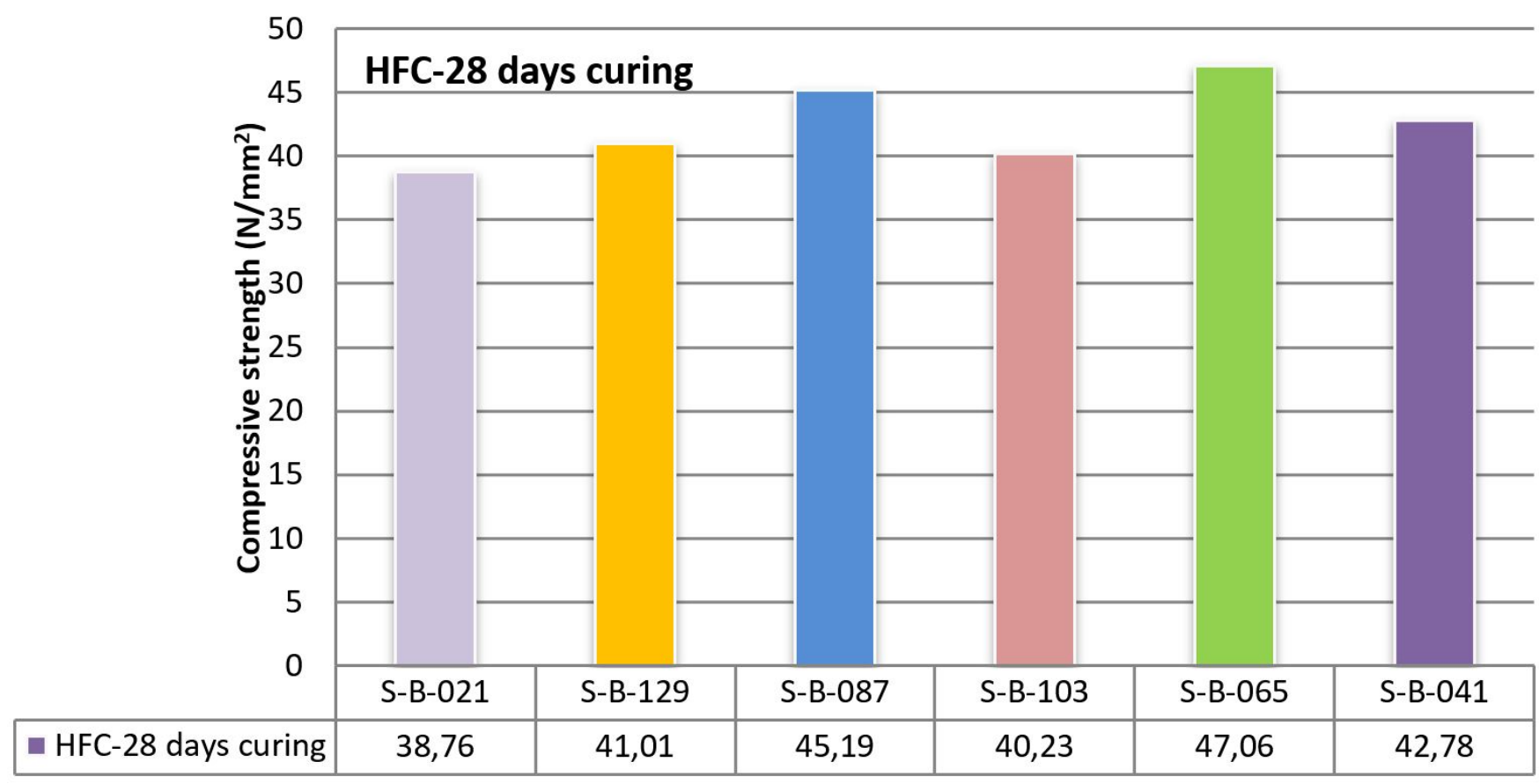

Figure 8. Compressive strength results of various hybrid fibre concrete mixes 


\subsection{Flexural characteristics of hybrid fibre concretes compared to plain concrete}

The complete flexural bending test results are provided in Table $\mathbf{7}$ and a detailed experimental result analysis using statistical software is subsequently explained in the following sections. The average flexural strength of reference concrete mix was found to be $5.20 \mathrm{~N} / \mathrm{mm}^{2}$ and this reference concrete was not considered in the statistical result analysis. Since the other two responses (toughness and ductility) was zero for a plain concrete system due to brittle nature and the complete absence of post peak curve due to sudden failure. Load - CMOD curves are drawn from the experimental values as shown in Figure $\mathbf{9}$ and the various fracture parameters are measured. Fracture strength was calculated from the peak load and fracture toughness was calculated from the entire load-deformation curve till failure. The toughness was calculated from the graph software. The experimental curves show different state of stressstrain plots depending upon the fibre content. However, the pre-peak strain hardening is influenced by the short brass fibres which are evidently seen in concrete mix S-B-065. Crack bridging of steel fibres were observed in concrete mix SB-129 which shows the fibre efficiency in terms of fibre availability required for crack closing forces. However, the hybrid fibre combinations containing high volume fraction of brass fibres also provided similar toughness values as compared to low volume fraction of steel fibres. Steel fibres were effectively bridging cracks without fibre rupture at high stress in post peak region as compared to finer and shorter fibres.

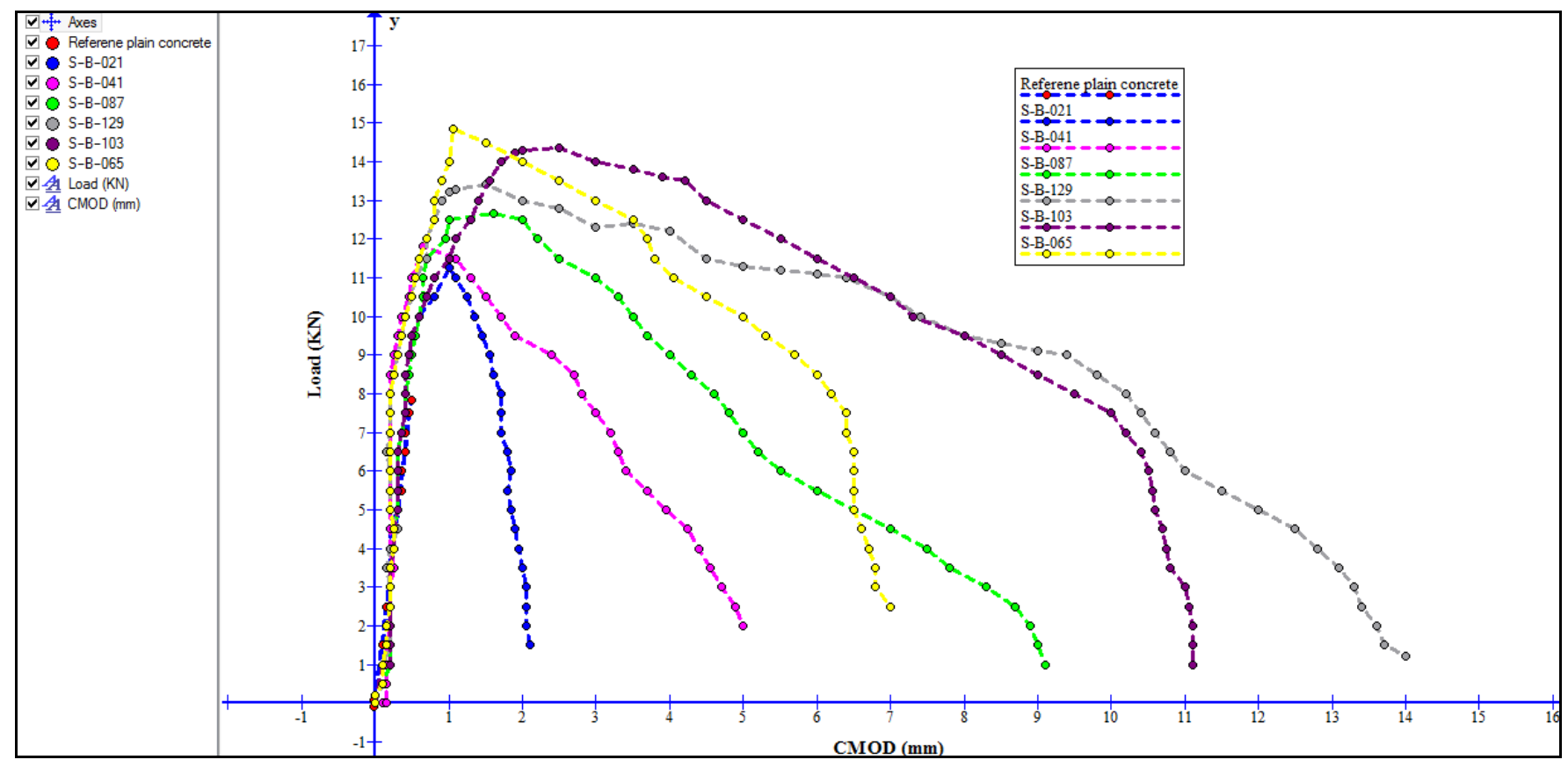

Figure 9. Load Vs. CMOD curves for various fibre concrete specimens

Hence, the test results of all hybrid fibre concretes as compared to reference concrete were evidently confirming the improvements on the flexural response with the fibre addition irrespective of type of fibre proportions. Fibres were evidently contributing for the overall increase in the pre-peak and post peak strain hardening of the hybrid fibre concrete mixes. The results of the load deformation tests are depicted in graphical form to understand the significant contribution of different fibre types and its relative presence in volume fraction (\%). The individual contributions of fibres on the corresponding improvements in concrete properties are analyzed using regression analysis and discussed in further sections. The sample calculations for determining the toughness using Graph software is given in Figure $\mathbf{1 0 .}$ 


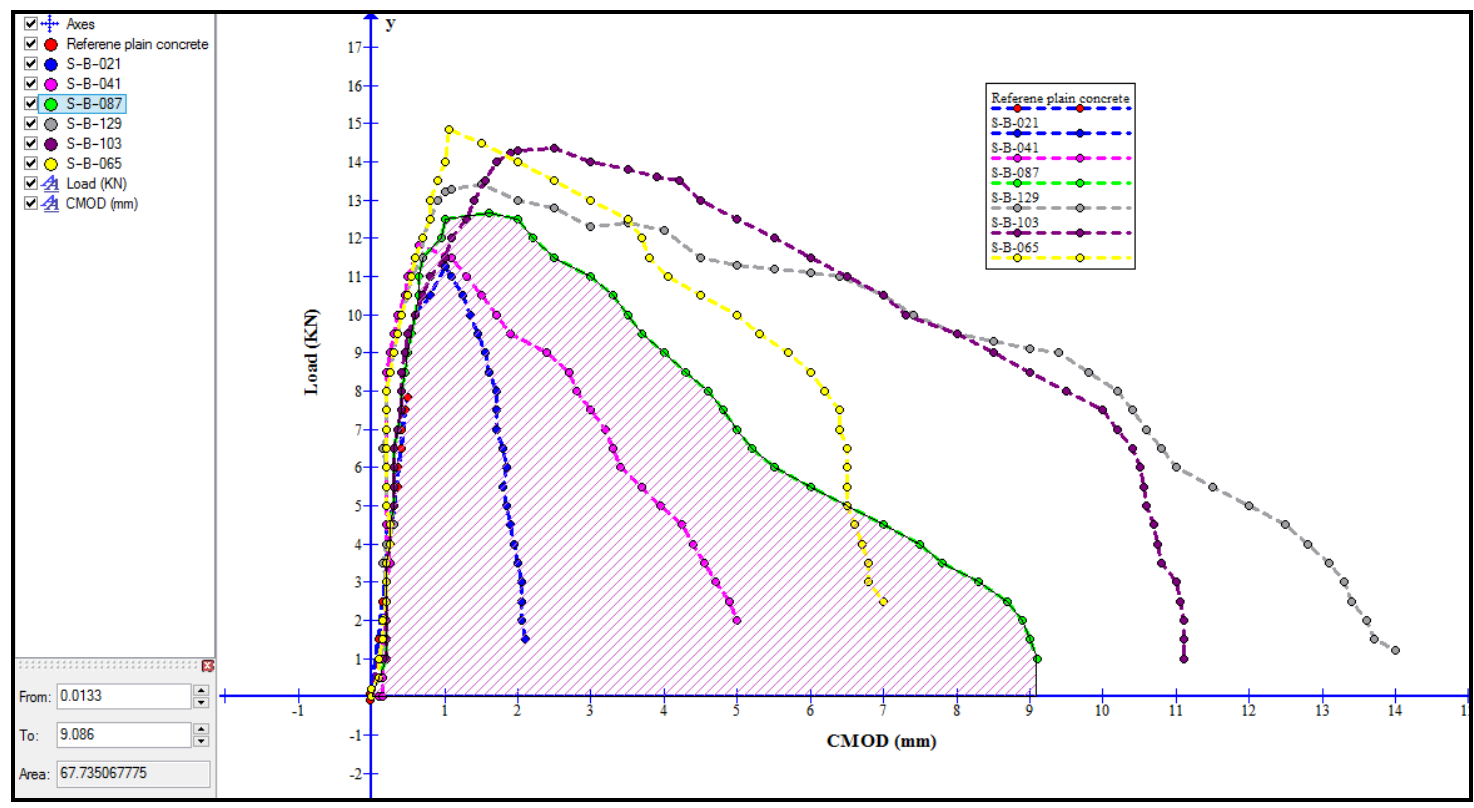

Figure 10. Fracture toughness calculation of various fibre concrete mixes using Graph software

The effect of fibre alignment and elastic modulus has significant influence on the flexural bending resistance of fibres aligned in the direction of axis of beam. Reasonable improvement in tensile load resistance is ensured by the fibres as loading axis lies to the normal plane [Yao, et al., 2003; Eethar \& Mahyuddin, 2011]. However, fibres in random distribution provided flexural properties not on par with that of aligned fibres. Homogenously distributed fibres in random direction envisage equal stress distribution in mutual orthogonal direction. But effective fibres contributing for stress sharing mechanism is limited as compared to aligned fibres. Fibres aligned normal to bending plane caters to the direct pullout load and hence stress is being shared effectively by fibres. This leads to either direct pullout or fracture of fibres and during this process, additional load resistance leads to improved fracture performance of the hybrid concretes.

Table 7. Flexural test results* of various hybrid fibre concretes

\begin{tabular}{|c|c|c|c|c|c|c|c|c|c|c|}
\hline \multirow[t]{2}{*}{ Mix ID } & \multirow[t]{2}{*}{$\begin{array}{c}\text { Fibre } \\
\text { orientation }\end{array}$} & \multirow[t]{2}{*}{ B/TA } & \multirow[t]{2}{*}{$\begin{array}{c}\text { Steel fibres } \\
(\%)\end{array}$} & \multirow[t]{2}{*}{$\begin{array}{c}\text { Brass } \\
\text { fibres (\%) }\end{array}$} & \multicolumn{2}{|c|}{$\begin{array}{l}\text { Flexural strength } \\
\left(\mathrm{N} / \mathrm{mm}^{2}\right)\end{array}$} & \multicolumn{2}{|c|}{$\begin{array}{l}\text { Fracture toughness } \\
\qquad(\mathrm{N}-\mathrm{m})\end{array}$} & \multicolumn{2}{|c|}{ Ductility (mm) } \\
\hline & & & & & Mean & S.D & Mean & S.D & Mean & S.D \\
\hline S-B-021 & random & 0.23 & 0.2 & 0.01 & 6.23 & 0.41 & 32.23 & 5.41 & 2 & 0.14 \\
\hline S-B-129 & aligned & 0.30 & 1.2 & 0.09 & 7.36 & 0.71 & 112.43 & 16.35 & 14 & 1.23 \\
\hline S-B-087 & aligned & 0.27 & 0.8 & 0.07 & 7.01 & 0.26 & 68.52 & 4.25 & 9 & 2.01 \\
\hline S-B-103 & random & 0.30 & 1.0 & 0.03 & 7.89 & 0.67 & 103.06 & 12.52 & 11 & 3.24 \\
\hline S-B-065 & random & 0.27 & 0.6 & 0.05 & 8.23 & 0.38 & 56.12 & 6.68 & 7 & 1.34 \\
\hline S-B-041 & aligned & 0.23 & 0.4 & 0.11 & 6.54 & 0.52 & 72.31 & 10.49 & 5 & 0.25 \\
\hline
\end{tabular}

Note * denotes the mean value of 5 samples tested for each response measured; S.D refers standard deviation.

\subsection{Statistical analysis on experimental results}

\subsubsection{Flexural strength}

The ANOVA result analysis of flexural test results indicated two important measurements namely F-statistics, which is a ratio of two variances and it,'s a measure of dispersion of data which are scattered from the mean. Also, the larger F-value in Table 8 shows greater dispersion due to randomized concrete mix variants. Similarly, the P-value represents the null hypothesis, which represents the level of significance of the fitted regression equation as well as the probability of the occurrence of a given event. The p-value of less than 0.05 as given in Table 8 shows the consistency of the regression equation for flexural strength. Since the $P$ value is less than 0.05 we reject the null hypothesis since no difference exist between the means and can be concluded that a significant difference does exist. The $\mathrm{P}$ values for B/TA ratio, Steel fibre volume fraction (\%), Brass fibre volume fraction (\%) and the fitted regression 
model are found to be below 0.05 the factors are significant. Whereas, in the case of fibre alignment the $P$ value was found to be over 0.05 , and can be termed as not a significant parameter. Since, fibre alignment is a categorical factor and has an indirect effect on the experimental design factors.

Table 8. ANOVA results of various responses

\begin{tabular}{|c|c|c|c|c|c|c|}
\hline \multirow{2}{*}{ Measured parameters } & \multicolumn{2}{|c|}{ Flexural strength } & \multicolumn{2}{|c|}{ Fracture toughness } & \multicolumn{2}{|c|}{ Ductility } \\
\hline & F-Value & P-Value & F-Value & P-Value & F-Value & P-Value \\
\hline Regression & 206.71 & 0.052 & 152.80 & 0.061 & 248.53 & 0.048 \\
\hline $\mathrm{B} / \mathrm{TA}$ ratio & 471.85 & 0.029 & 0.09 & 0.813 & 0.30 & 0.682 \\
\hline Steel fibre volume fraction (\%) & 327.84 & 0.035 & 5.37 & 0.259 & 18.35 & 0.146 \\
\hline Brass fibre volume fraction (\%) & 213.29 & 0.044 & 0.51 & 0.604 & 2.75 & 0.346 \\
\hline Fibre Alignment & 0.58 & 0.586 & 77.78 & 0.072 & 0.00 & 0.992 \\
\hline $\mathrm{R}-\mathrm{sq}(\%)$ & \multicolumn{2}{|c|}{99.8} & \multicolumn{2}{|c|}{99.8} & \multicolumn{2}{|c|}{99.9} \\
\hline R-sq (pred) (\%) & \multicolumn{2}{|c|}{90.7} & \multicolumn{2}{|c|}{87.5} & \multicolumn{2}{|c|}{92.3} \\
\hline Std. deviation ( $\left.\mathrm{N} / \mathrm{mm}^{2}\right)$ & \multicolumn{2}{|c|}{0.34} & \multicolumn{2}{|c|}{11.40} & \multicolumn{2}{|c|}{1.16} \\
\hline Coefficient of variance (\%) & \multicolumn{2}{|c|}{5.62} & \multicolumn{2}{|c|}{34.15} & \multicolumn{2}{|c|}{23.01} \\
\hline
\end{tabular}

The ANOVA results of fracture toughness showed higher dispersion value (F-value) for fibre alignmentas given in Table 8. Compared to other parameters which affect the test results the fibre alignment had shown conspicuous $P$ value of less than 0.072 which reject the null hypothesis and can be concluded that a significant difference does exist. The ANOVA result analysis of ductility had indicated higher F-value for steel fibre dosage as given in Table $\mathbf{8}$ which showed higher dispersion. Compared to other parameters, which affect the test results, fibre alignment had shown a Pvalue of less than 0.048 which can reject the null hypothesis and can be concluded that a significant difference does exist. In general, all the factors do have direct influence on the various responses depending on the type of mechanical property measured.

\subsection{Regression Model/ Equation}

Regression analysis is a powerful statistical method which is useful for evaluating the relationship between two or more parameters. It can be used to predict the flexural strength of a fibre reinforced concrete for both aligned and randomly distributed fibre dispersion in concrete. The below regression Equations $\mathbf{3}$ to $\mathbf{8}$ quantifies the aligned and randomly distributed steel-brass hybrid fibre concretes respectively.

i) Flexural strength

\begin{tabular}{ccc}
\hline $\begin{array}{c}\text { Fibre } \\
\text { Alignment }\end{array}$ & & \\
\hline Aligned, & Flexural Strength $=$ & $\begin{array}{c}-18.35+113.08 \text { B/TA ratio }-8.313 \text { Steel fibre volume fraction (\%) } \\
\end{array}$ \\
& +19.92 Brass fibre volume fraction (\%) (3) \\
Random, & Flexural Strength $=$ & $-18.30+\begin{array}{c}113.08 \mathrm{~B} / \text { TA ratio }-8.313 \text { Steel fibre volume fraction (\%) } \\
+19.92 \text { Brass fibre volume fraction (\%) (4) }\end{array}$ \\
\hline
\end{tabular}

ii) Fracture toughness

\begin{tabular}{|c|c|c|c|}
\hline \multicolumn{4}{|c|}{ Fibre Alignment } \\
\hline Aligned & Fracture toughness $(\mathrm{N}-\mathrm{m})$ & $=$ & $\begin{array}{c}31.7+71 \text { B/TA ratio + } 47.7 \text { Steel fibre volume fraction (\%) } \\
+43.9 \text { Brass fibre volume fraction }(\%)(5)\end{array}$ \\
\hline Random & Fracture toughness $(\mathrm{N}-\mathrm{m})$ & $=$ & $\begin{array}{c}6.8+71 \text { B/TA ratio }+47.7 \text { Steel fibre volume fraction }(\%) \\
+43.9 \text { Brass fibre volume fraction }(\%)(6)\end{array}$ \\
\hline
\end{tabular}

iii) Ductility

Fibre

Alignment 


$\begin{array}{cccc}\text { Aligned } & \text { Ductility }(\mathrm{mm})= & -3.52+14.4 \mathrm{~B} / \mathrm{TA} \text { ratio }+9.98 \text { Steel fibre volume fraction }(\%) \\ & +11.46 \text { Brass fibre volume fraction }(\%)(7)\end{array}$

R-square value given in Table 8 represents the goodness-of-fit measure for linear regression models and provides essentially the validity of the regression equations. $\boldsymbol{R}$-squared also represents a statistical measure of how close the experimental data are to the fitted regression line. Since the model value and predicted $R^{2}$ value is above $90 \%$ for all the fitted regression equation which indicates the model adequacy to explain all the variability of response data around its mean.

\subsection{Effects of various factors on the various observed responses}

\subsubsection{Main factor effects}

The various main factor effects plot on the flexural strength charactersitics of fibre concretes are provided in Figure 11. The experimental trend lines of individual factors shows the variation of flexural strength. It can be noted that the effect of fibre alignment has significant advantage on the improvement in flexural strength. Similarly, the effects of increasing the binder to aggregate ratio (0.27 to 0.30$)$ in the concrete mix had shown an increase in the flexural strength $\left(7.89\right.$ to $\left.8.23 \mathrm{~N} / \mathrm{mm}^{2}\right)$. Experimental trends also clearly indicated that the presence of brass fibre volume fraction were significant to increase the flexural strength as compared to steel fibres. The flexural strength increase was noticeable when the steel fibre content $(0.6 \%)$ in hybrid fibre concretes was kept lower with the brass fibre volume $(0.05 \%)$ at optimum addition. Even though the fineness of brass fibres does essentially contribute for the overall increase in flexural strength; its optimum fibre content envisages for its matrix reinforcement. Hence, more presence of brass fibres do affect the integrity of concrete and thereby resulting in poor matrix densification due to weak interface void formation.

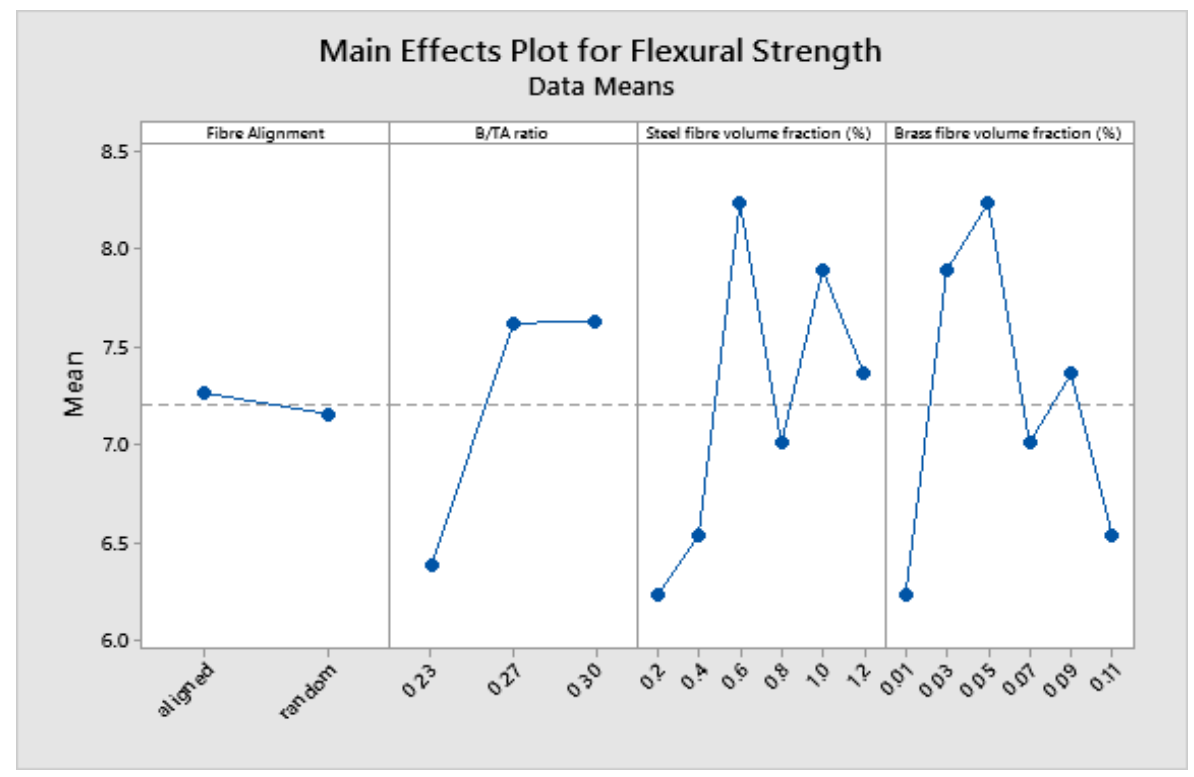

Figure 11. Main factor effect plot for flexural strength

The area under the entire Load - CMOD curves (as seen in Figure 10) of concrete specimens were essentially used for the estimation of fracture toughness values. The area under the entire toughness of concrete indicates the energy absorbing capacity of concrete and hence the large post peak deformation characterized by high-energy absorbing capacity. Experimental trendlines in Figure $\mathbf{1 2}$ indicate that the maximum presence of steel fibres actually contribute for the improvement of the toughness value [Chen \& Liu, 2004]. Most importantly, the synergistic action of hybrid fibres had witnessed good improvements on the toughness value especially when the hybrid fibre combinations of high steel-low brass fibres and low steel-high brass steel fibres are used. This increase in toughness value is primarily due to longer steel fibres at high volume fraction which helps in high energy required during fibre pullout or ruptures 
embedded in the matrix [Wang et al, 2001]. Similarly, the large presence of brass fibres contribute for the effective fibre bridging at large crack widths formed at post peak deformation.

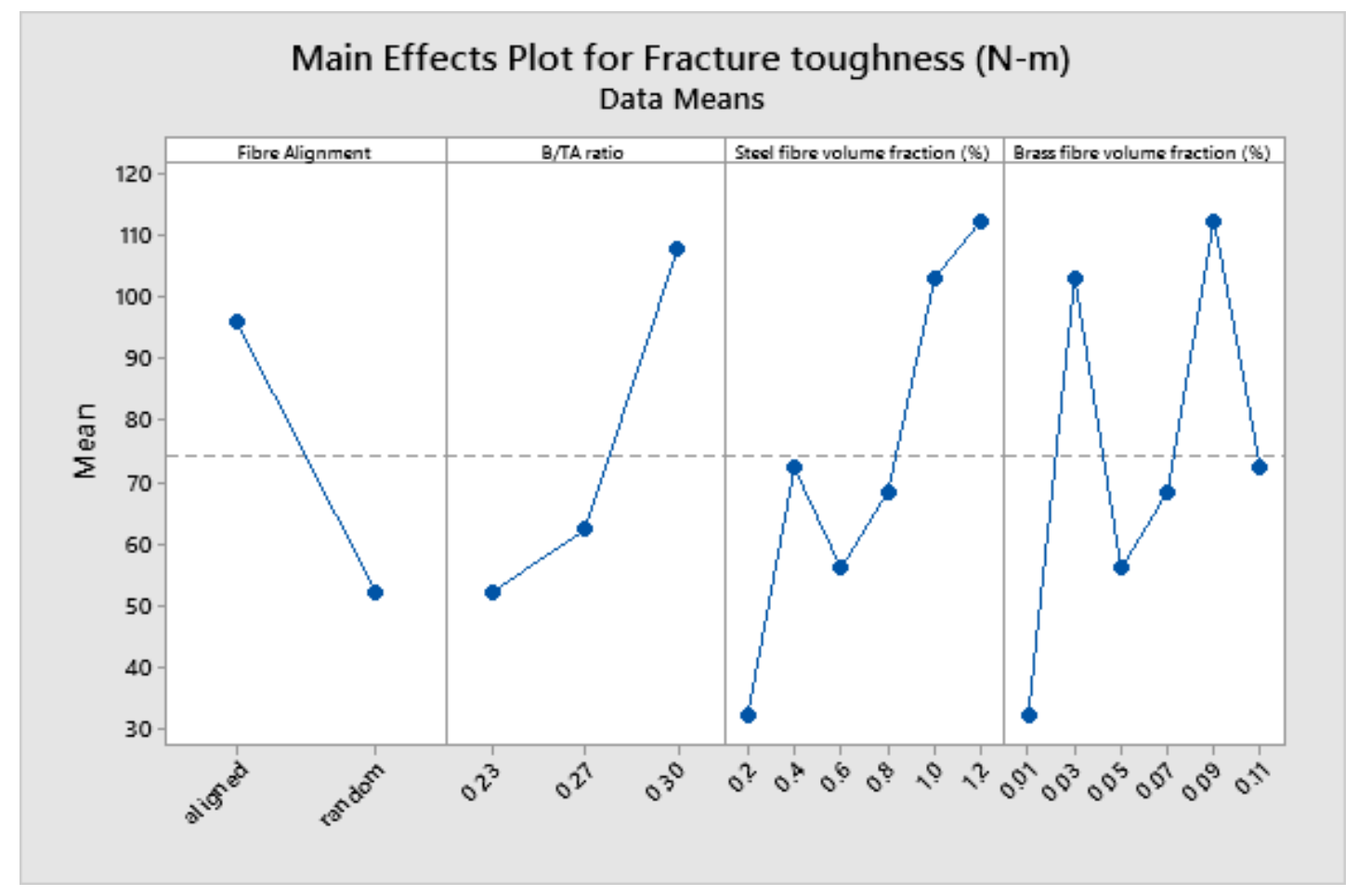

Figure 12. Main factor effect plot for fracture toughness

Post-elastic deformation of the various concrete specimens is measured from Figure 10 and represented using main factor effect plot on ductility in Figure 13. The amount of strain sustained by fibre concrete specimens upon cracking is referred to as ductility. During the post elastic bending process, the stress transfer mechanism was essentially taken care by the fibres from the matrix interface without sudden drop in load carrying capacity [Sun et al., 2001]. Depending upon the amount of fibre availability, the sudden drop in stress carrying capacity may be controlled. The maximum ductility was measured in case of high dosage of steel fibre volume fraction and the hybrids containing high steel-low brass fibre (S-B-129) concrete specimens. However, ductility of concrete was also noticeably increased with high steel-low brass fibre (S-B-103) combinations. This indicates large brass fibre availability in the crack front which can dissipate more fracture energy around the crack vicinity. 


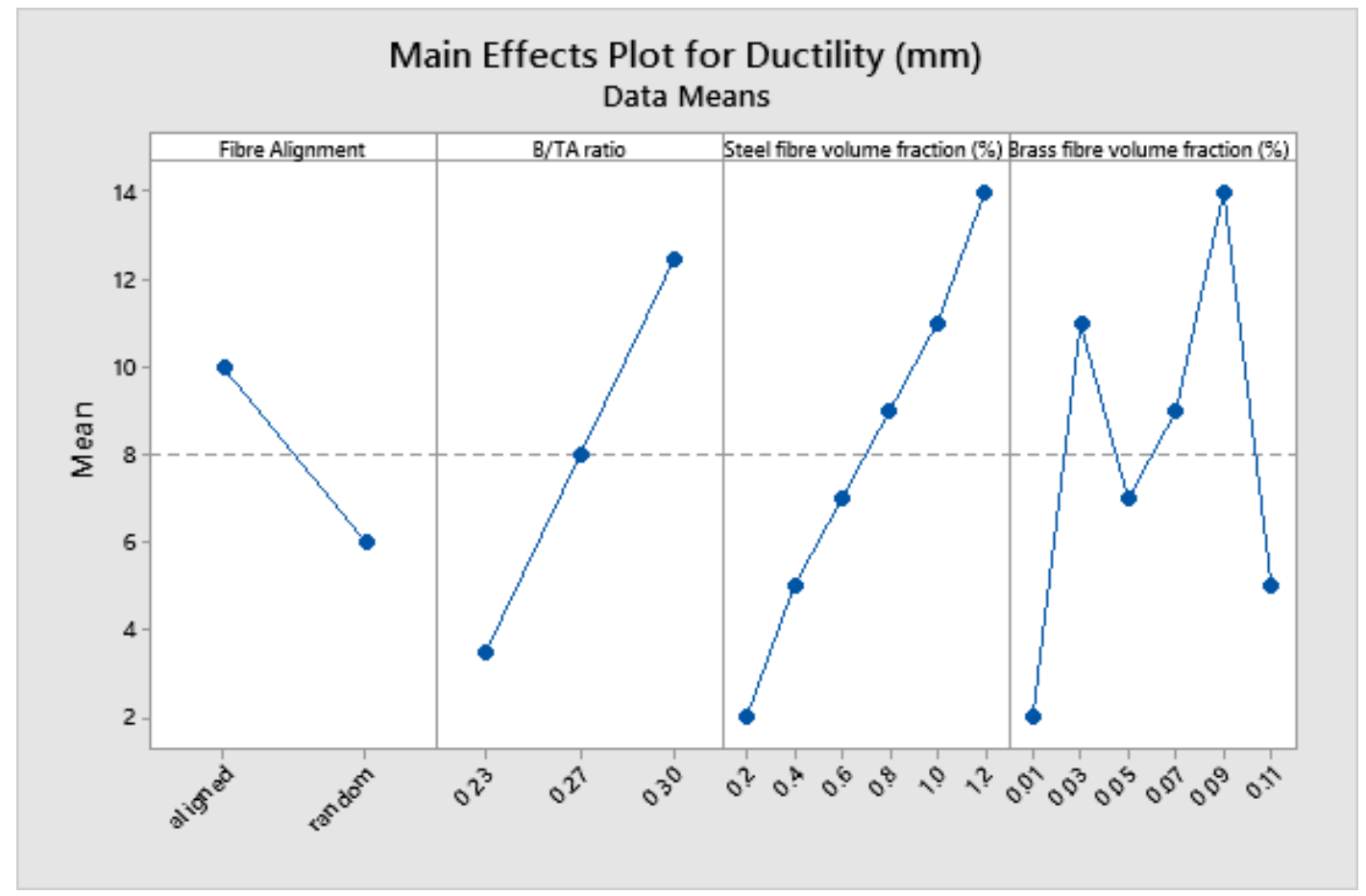

Figure 13. Main factor effect plot for ductility

\subsubsection{Interaction effects of various factors}

The influence of measured responses among different factors can be more appropriately defined in terms of interaction effects. It can be noted from Figure $\mathbf{1 4}$ that, an interaction effect between various measured parameters exists if the trend lines cross each other. This can be noticed from the graphical trendlines provided in Figure 14 that, the interaction effects exist between binder to aggregate ratio and the fibre alignment. Significant difference in aligned and random fibres was noticed from the interaction trendlines. Interaction effects were noticed in the case of binder to aggregate ratio and fibre alignment; since the change in matrix properties affects the flexural strength. A significant flexural strength increase was observed with an increase in the binder to aggregate ratio accompanied by fibre alignment. However, no interaction exists between steel fibres and binder to aggregate ratio as the steel fibres are longer and upon matrix micro-cracking the stress transfer mechanism is dependent on fibre length. However, the interaction effects were pronounced for binder to aggregate ratio and brass fibre volume; as the fibres are finer and essentially forms an integral part of the matrix. Thus, subsequent matrix strengthening accounting for composite mix interaction between binder to aggregate ratio and brass fibres was noticed. Thus, interaction trends clearly show that the brass fibres had shown direct influence on strength compared to steel fibres. Hence, the optimum volume fraction of brass fibres combined with steel fibres showed consistently higher flexural performance. 


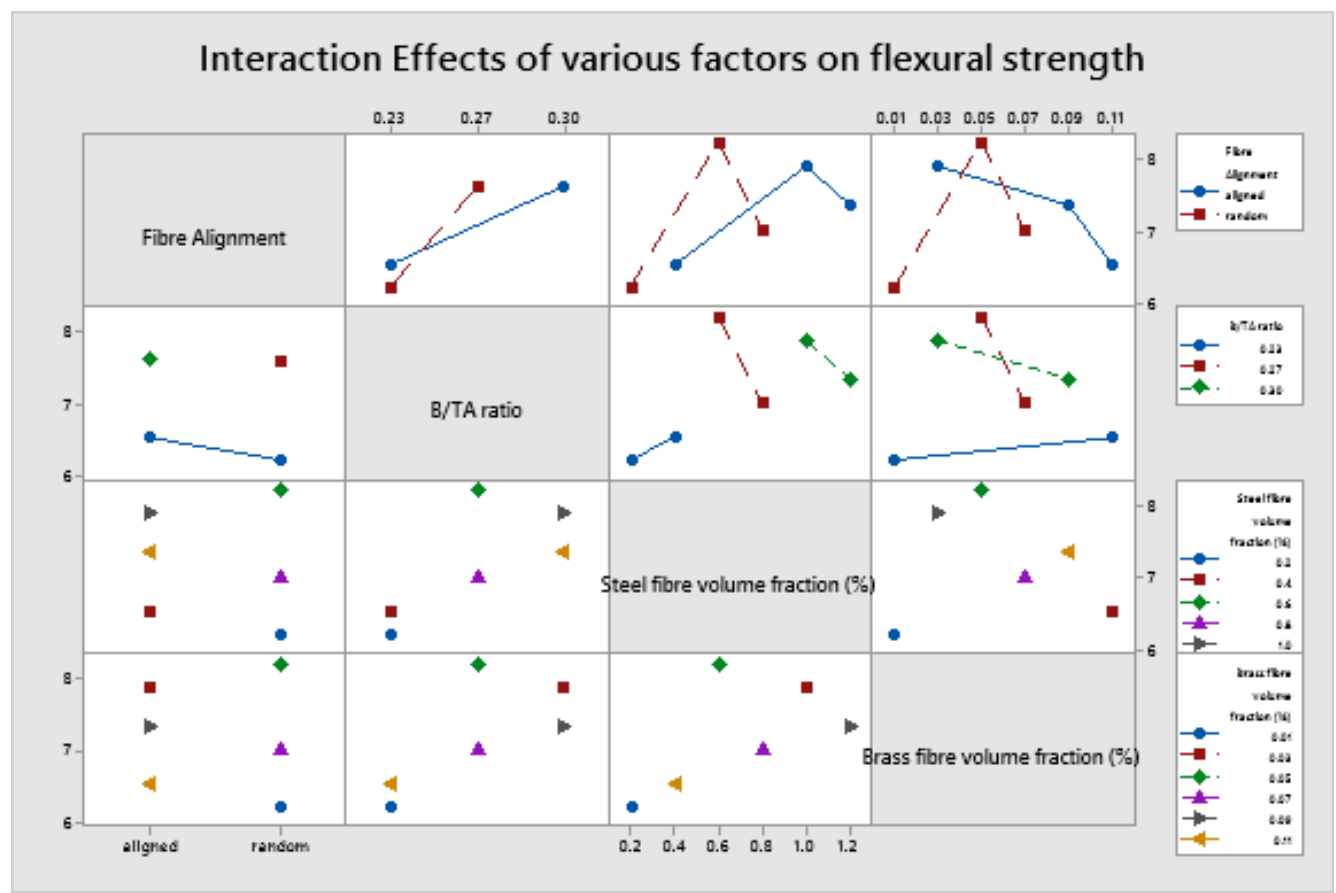

Figure 14. Interaction effects of various factors on flexural strength

Interaction curves show the significance of various parameters in relation to the measured response. In the case of interaction effects of flexural toughness as provided in Figure 15, there were no crossovers of trend lines as observed from the interaction effects. Trend lines signify that the factor binder to aggregate ratio is independent or less influential on the overall improvement of toughness. Whereas, the effect of steel fibres are more phenomenal on the toughness improvement as the steel fibres are longer and possess high elastic modulus. As toughness measures the post elastic deformation which accounts for longer steel fibres with high elastic modulus [Buratti etal., 2011].

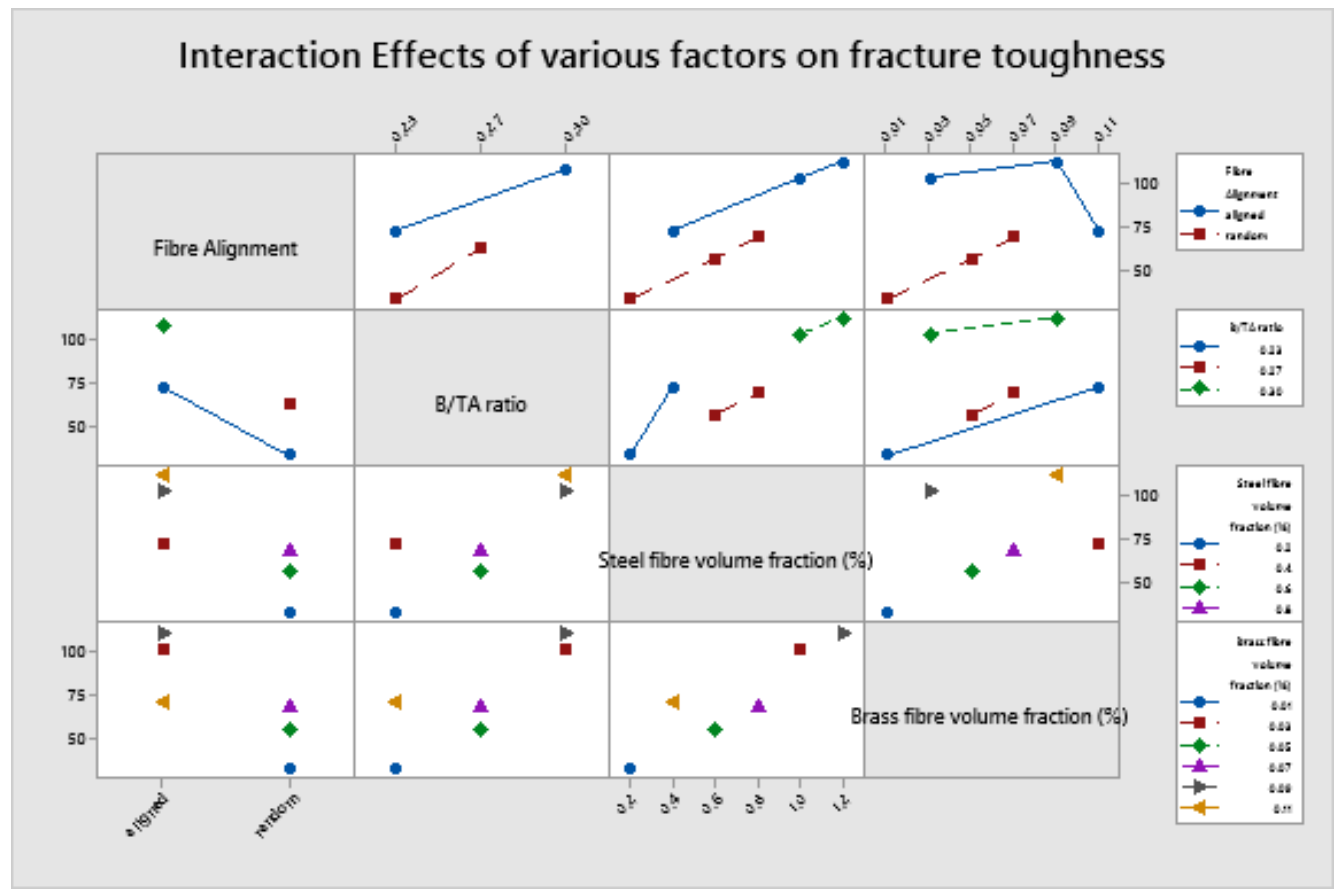

Figure 15. Interaction effects of various factors on fracture toughness

On the other hand brass fibres at low volume fraction does not compensate for significant crack closing at larger crack widths. In the case of ductility, the interaction effects represented in Figure $\mathbf{1 6}$ revealed that the trend lines were parallel. Moreover, ductility of aligned fibres is far superior to randomly distributed fibres due to the fact that fibres experience direct stress. 


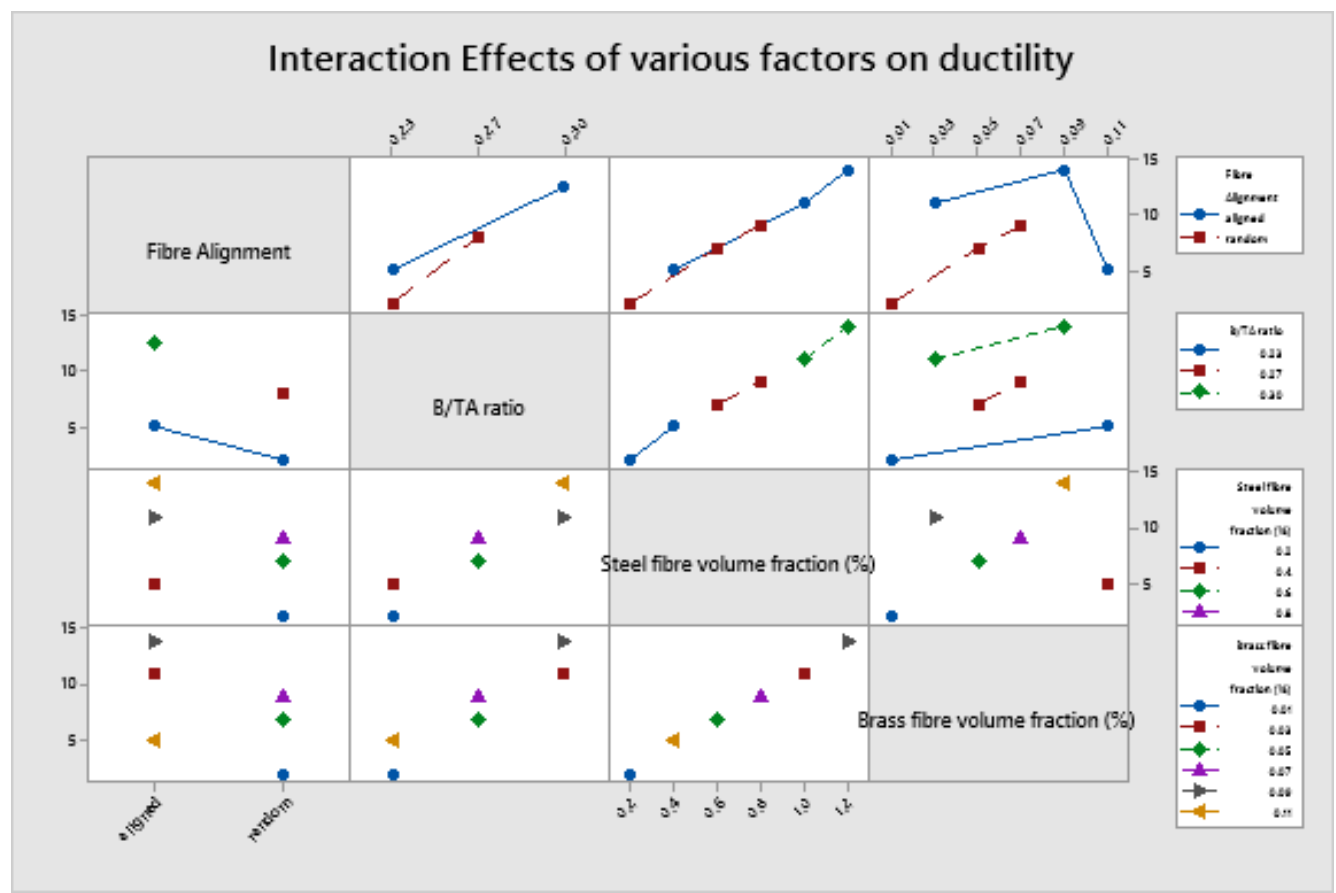

Figure 16. Interaction effects of various factors on ductility

\subsection{Contour plots}

Contour plots are two-dimensional non-linear curved plots obtained from the experimental results. The variation of measured responses w.r.t various factors are represented in contour plots, which can provide a wide range of individual factors that, affects the measured responses. The contour plot showed (Figure 17) a maximum response for the flexural strength when a binder to aggregate ratio of 0.27 and steel fibre volume fraction of 0.6 is adopted.

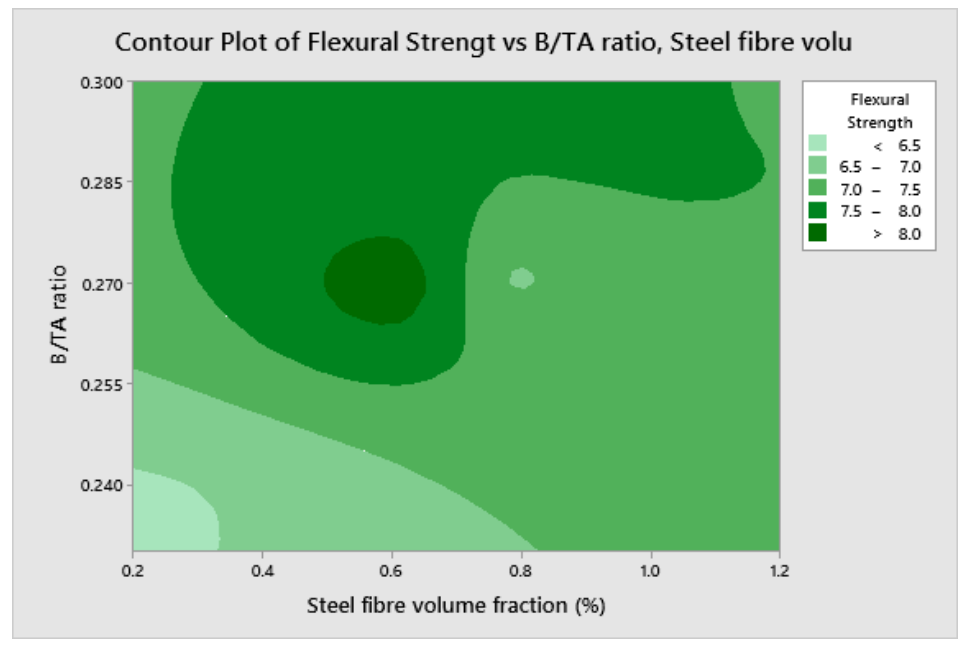

Figure 17. Contour plot variation for flexural strength - B/TA Vs. Steel fibre volume fraction

Similarly, contour plots provided in Figure 18 shown that fracture toughness was maximum for B/TA of 0.3 and steel fibre volume of 1.2. This similarity was also noticed in ductility as seen in the contour plot represented in Figure 19. These trends confirm that both the measured responses (toughness and ductility) are function of post elastic deformation or self straining of high elastic modulus steel fibres. Also, the flexural strength is maximum when the steel fibre volume and brass fibre volume are kept at optimum level of $0.6 \%$ and $0.05 \%$ respectively. Fracture toughness is maximum when the brass fibre volume fraction is in the range of $0.08 \%$ to $0.10 \%$ and steel fibre volume of $1.1 \%$ to $1.2 \%$. Ductility is maximum when steel fibre and brass fibre volume fractions are at $1.2 \%$ and $0.09 \%$ respectively. 


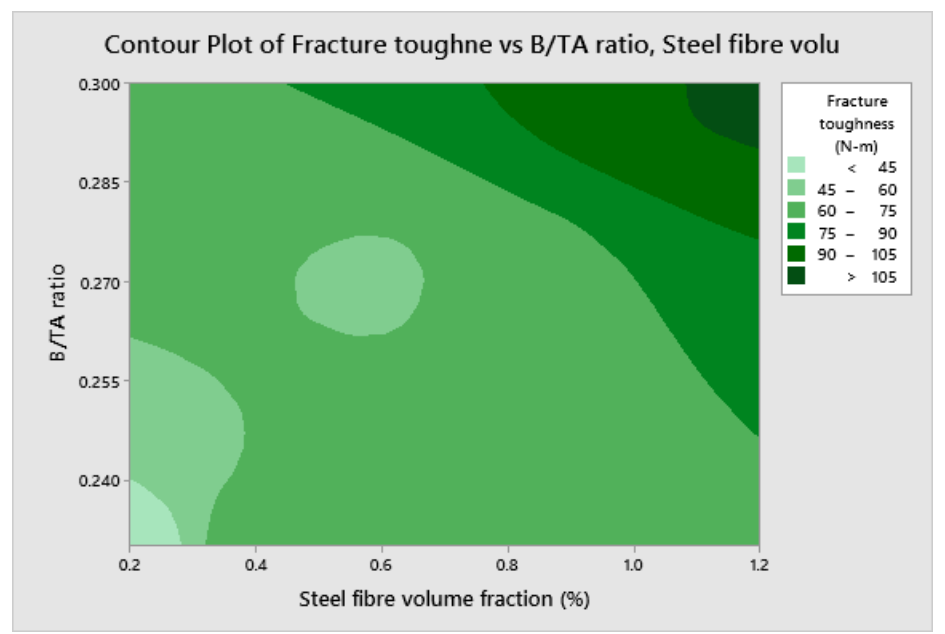

Figure 18. Contour plot variation for fracture toughness - B/TA Vs. Steel fibre volume fraction

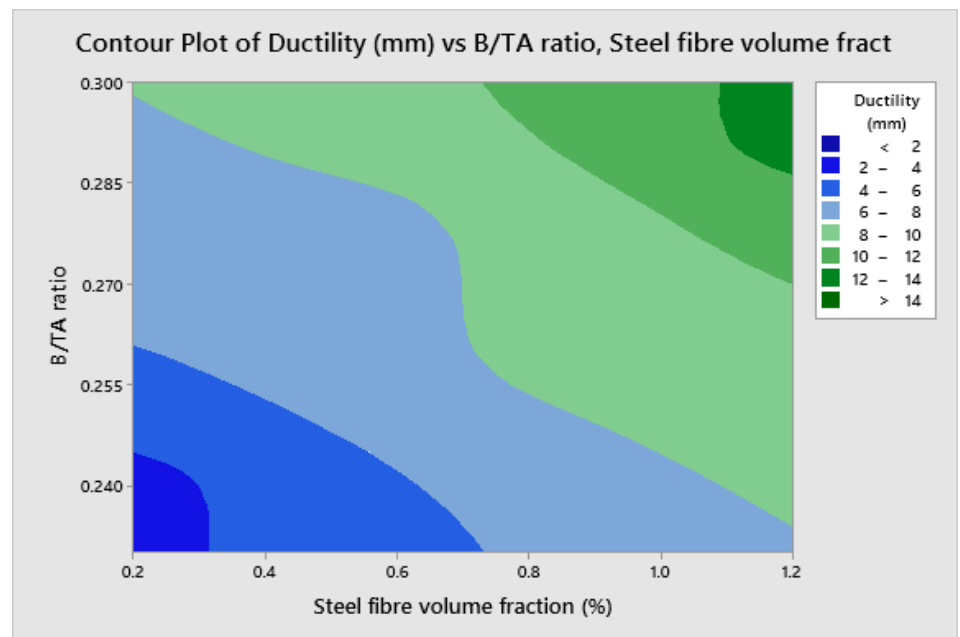

Figure 19. Contour plot variation for fracture toughness - B/TA Vs. Steel fibre volume fraction

\subsection{Comparative analysis of various hybrid fibre concretes}

The variations of flexural strength, toughness and ductility over a wide range of hybrid fibreconmbintaions are provided in the contour plots.It can be noted from Figure $\mathbf{2 0}$ that, the addition of steel fibres at low volume fraction $(0.6 \%)$ and brass fibres at optimal volume fraction $(0.05 \%)$ provided enhanced composite flexural strength compared to other fibre combinations. Also, the high volume fractions of steel $(1.2 \%)$ and brass fibres $(0.09 \%)$ contribute for the overall increase in toughness and ductility of the composite system as evidently seen from the contour plots in Figures 21 and 22. Hence it can be cocluded that fibre combinations with steel and brass combinations at optimal volume fractions ( 1 to $1.2 \%$ steel fibre and 0.05 to $0.09 \%$ brass fibre) showed a reliable increase on the overall fibre synergy. The contour plots indicated that fibre synergy in concrete improves with the type of hybrid fibre combinations. 


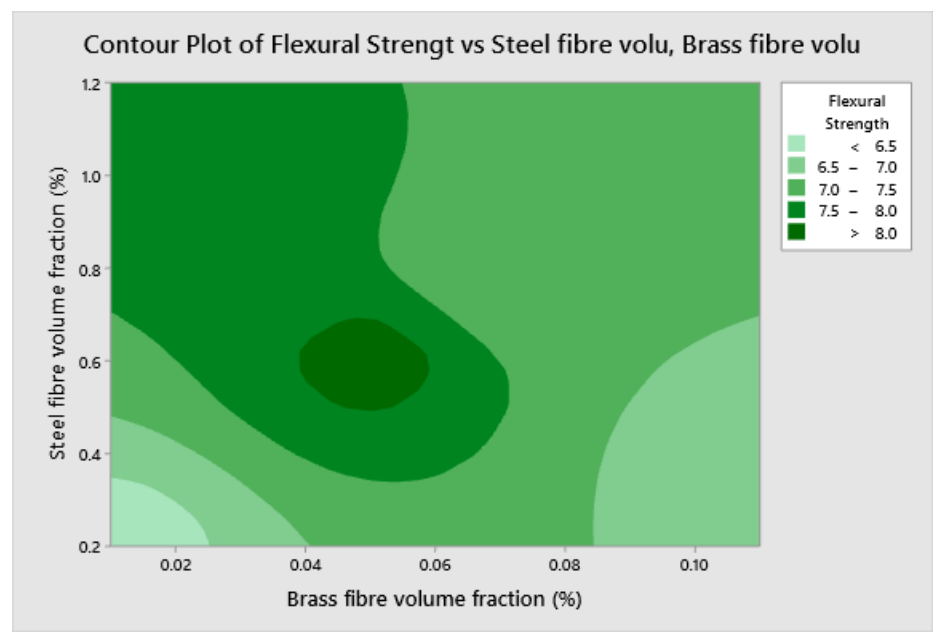

Figure 20. Contour plot variation for flexural strength - Steel fibre vs. Brass fibre

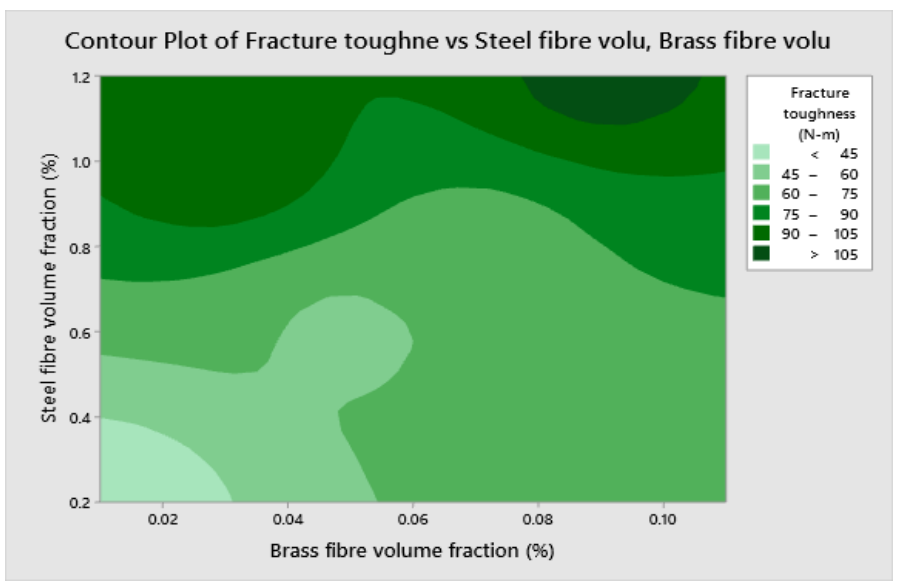

Figure 21. Contour plot variation for fracture toughness - Steel fibre vs. Brass fibre

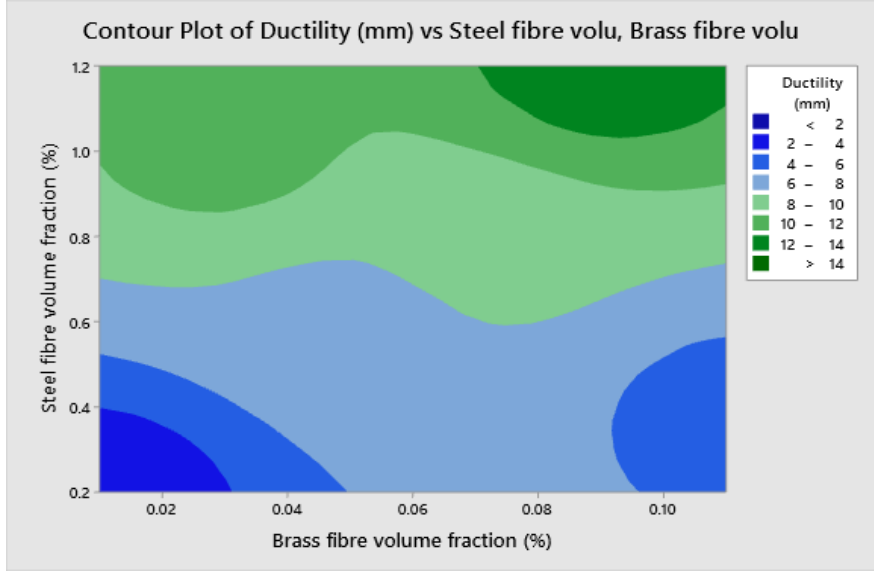

Figure 22. Contour plot variation for ductility - Steel fibre vs. Brass fibre

\subsection{CONCLUSIONS}

Fibre addition had shown a favorable increase in mechanical strength and thereby resulted in improved crack resistance compared to plain concrete specimens. The resulting crack growth at higher loading eventually resulted in unstable crack growth propagation leading to unwarranted failure. Fibres of different sizes and types had shown promising results on the overall improvement of the concrete properties. The ANOVA results thus confirm the property of fibre addition in plain concrete systems. 
a) Fibre addition had shown marginal strength enhancement compared to plain concrete; as fibres do not contribute directly in crushing due to non- straining of fibres in fracture plane other than bending. However, the strength increase in hybrid fibre concretes is not originally due to dual action of steel-brass fibres. But it can be justified that finer brass fibres do originally contribute for matrix strengthening and hence the marginal strength increaseupto $8 \%$ occurred in case of steel-brass fibres of $0.6 \%$ and $0.05 \% \mathrm{~V}_{\text {frespectively. }}$

b) Maximum flexural strength $\left(8.23 \mathrm{~N} / \mathrm{mm}^{2}\right)$ was observed for hybrid concretes containing fibre combinations of steel-brass@ @ $0.6 \%$ and $0.05 \%$ volume fraction respectively. The effect of fibre orientation (aligned) has promulgated for toughness increase in post peak compared to pre peak strain hardening. This suggests that before matrix cracking the strengthening effect in matrix is originally contributed for fibres in random orientation. Fibres in aligned direction do have little effect in crushing failure as the fibres does not undergo self-straining.

c) Statistical ANOVA results support the characteristic behavior of different hybrid fibre concretes. As the randomized experiments are useful to predict the mechanical response of crossover combinations of different hybrids, the regression equations are useful for point predictions.

d) Toughness and ductility of hybrid composite is a function of elastic modulus of steel fibres and volume fraction. Hence, maximum toughness $\left(112.43 \mathrm{~N}-\mathrm{m}\right.$ ) is noticed for steel-brass hybrids of $1.2 \% \mathrm{~V}_{f}$ and $0.9 \mathrm{~V}_{\mathrm{f}}$ respectively. Fibre alignment has significant effect on the post crack yielding (ductility) of hybrid concretes. As compared to random orientation, the fibre alignment along beam axis promulgates large strain till failure (without loss in stress carrying capacity). Hence, maximum ductility of $14 \mathrm{~mm}$ was obtained for steel-brass hybrid fibre concretes (S-B-129) with maximum volume fraction of steel (1.2\%) and brass fibre $(0.9 \%)$.

e) The different point predictions and arriving optimal fibre combinations are evidently correlated in contour plots.

e) The effects of various factors in terms of main effects and its corresponding inter dependence is better correlated from the interaction charts.

\section{Acknowledgements}

The authors gratefully acknowledge the Deanship of Research, King Khalid University for providing financial support for this project (No.12) under the faculty sponsored research program.

Author's Contribuitions: Conceptualization, S Anandan; Methodology, S Anandan; Investigation, S Anandan and M Alsubih; Writing - original draft, S Anandan and M Alsubih; Writing - review \& editing, S Anandan and M Alsubih; Funding acquisition, S Anandan and M Alsubih.

Editor: Marcílio Alves.

\section{References}

Balaguru, P. N \& Shah S P. (1992). Fiber Reinforced Cement Composites, McGraw-Hill Inc.

Bentur, A., \&Mindess, S. (1990). Fibre Reinforced Cementitious Composites, Elsevier, London.

Yoo, D.Y, Shin, H.O, Yang, J.M., \&Yoon, Y.S. (2014). Material and bond properties of ultra high performance fiber reinforced concrete with micro steel fibers, Composites-B, 58, 122-133.

Markovic, I., Van Mier, J., \&Walraven, J.C. (2004). Tensile behaviour of high performance hybrid fibre concrete, Proceedings of the 5th International Symposium on Fracture Mechanics of Concrete and Concrete Structures, Vail Colorado, Vol.2, 11131121.

Olivito, R.S., \&Zuccarello, F.A. (2010). An experimental study on the tensile strength of steel fiber reinforced concrete. Compos B;41(3), 246-55.

Peng, Z., Song, H., Serina N.G., \& Xu-Hao, W. (2018). Fiber-Reinforced Concrete with Application in Civil Engineering, Article ID 1698905, Advances in Civil Engg. 1-4. 
Dancygier, A.N., \& Savir, Z. (2006). Flexural behavior of HSFRC with low reinforcement ratios, Engineering Structures, 28, $1503-$ 1512.

Yoo, D.Y., Yoon, Y.S., \&Banthia, N. (2015). Flexural response of steel-fiber-reinforced concrete beams: effects of strength, fiber content, and strain-rate, Cement \& Concrete Composites, 11 (64), 84-92.

Machine, H., Chijen, T., \& Song, P.S. (2008). Mechanical Properties of Polypropylene Hybrid Fiber Reinforced Concrete, Materials Science and Engineering, 494, 153-157.

Quian, C.X. \&Stroeven, P. (2000). Development of Hybrid Polypropylene-Steel Fibre Reinforced Concrete, Cement and Concrete Research, 30, 63-69.

Kaan, T., Umut, H., Tamer, B., Altug, Y., \&Halit, Y. (2019). Hybrid fiber use on flexural behavior of ultra high performance fiber reinforced concrete beams, Composite structures, Volume 229, No.1, Article ID.111400.

Dancygier, A.N., \&Berkover, E. (2016). Cracking localization and reduced ductility in fiber-reinforced concrete beams with low reinforcement ratios, EngineeringStructuctures, 111, 411-424.

Gao, D., Jing, J., Chen, G. \& Yang, L. (2019). Experimental investigation on flexural behavior of hybrid fibers reinforced recycled brick aggregates concrete, Construction and Building Materials, Volume 227, 10 December 2019, 116652.

Banyhussan, Q.S., Yıldıım, G., Bayraktar, E., Demirhan, S., \& Şahmaran, M. (2016). Deflection-hardening of hybrid fibers reinforced concrete: The effect of aggregate content, Construction \& Building Materials, 10 (125), pp. 41-52.

Soner, G., Demet Y., Fuat, K.,\&Ashraf, A. (2019). Strength prediction models for steel, synthetic, and hybrid fiber reinforced concretes, Structural Concrete, 20, 428-445.

ACI 544.4R-18 (2018). Guide to Design with Fiber-Reinforced Concrete", Farmington Hills, MI 48331

ASTM C39 / C39M (2018). Standard Test Method for Compressive Strength of Cylindrical Concrete specimens, ASTM International, West Conshohocken, PA, 2018, www.astm.org.

RILEM, T.C. (1985). Determination of the fracture energy of mortar and concrete by means of three-point bend tests on notched beams. Materials and Structures, 18(106):285-290.

Vandewalle. L., Nemegeer, D., Balazs, L., Barr, B., Barros. J., \& Barros, P. (2002). Recommendation of RILEM TC162-TDF: Test and design methods for steel fiber reinforced concrete: final recommendation for bending test, Materials and Structures, Vol.35, 579-582.

Yao, W., Li, J., \&Wu, K. (2003). Mechanical Properties of Hybrid Fiber-Reinforced Concrete at Low Fiber Volume Fraction, Cement and Concrete Research 33, 27-30.

Eethar, T. D., \& Mahyuddin, R. (2011). Contribution of Hybrid Fibers on the Properties of High Strength Concrete Having High Workability, Procedia Engg., Volume 14, 814-820.

Chen, B., \& Liu, J. (2004). Residual strength of hybrid-fiber-reinforced high-strength concrete after exposure to high temperatures. Cement \& Concrete Research, 34, 1065-69.

Wang, Z.L., Wu, J., \&Wang, J.G. (2001). Experimental and numerical analyses on effect of fiber aspect ratio on mechanical properties of SRFC, Constr. Build Mater, 24(4):559-65.

Sun, W, Chen, H., Luo, X., \& Qian, H. (2001). The effect of hybrid fibers and expansive agent on the shrinkage and permeability of high-performance concrete, Cement \& Concrete Research, 31, 595-601.

Buratti, N., Mazzotti, C., \&Savoia, M. (2011). Post-cracking behavior of steel and macro-synthetic fibre-reinforced concretes, Construction \& Building Materials, 25, 2713-2722. 